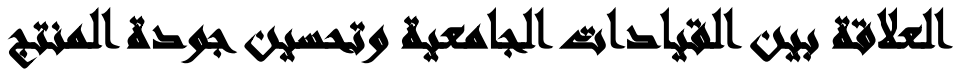

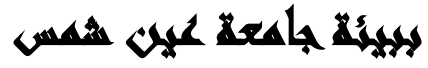

سماح رجب عبد القادر(')- عاطف عبد الحميد حسن(؟) أسامة محمود فريد(r)

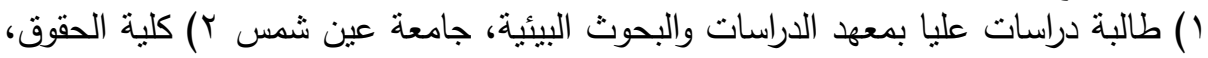

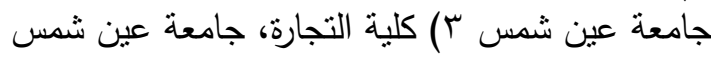

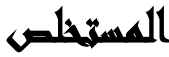

يهدف البحث الحالى الى تحديد مفهوم الجودة داخل نظام ضمان الجودة الداخلى الجئ

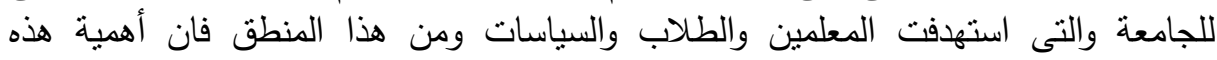

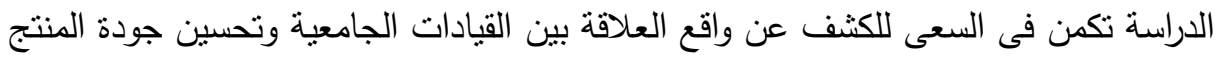

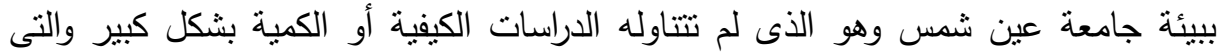
حاولت الدراسة الراهنة سد الثغرات النظرية والكمية لموضوع الدراسة. حيث استخدم الباحثون

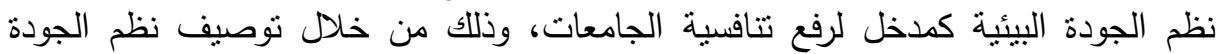

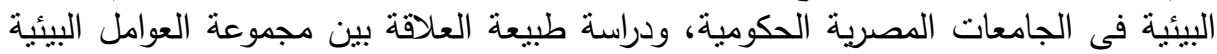

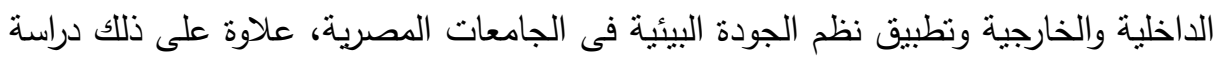

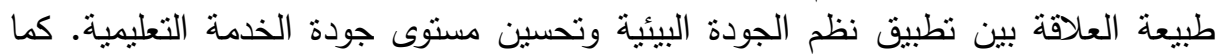

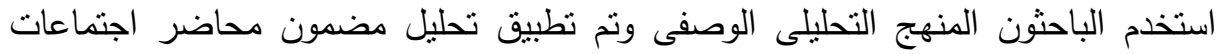

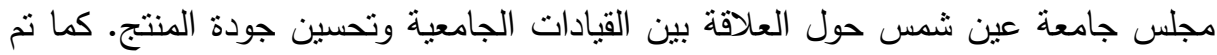

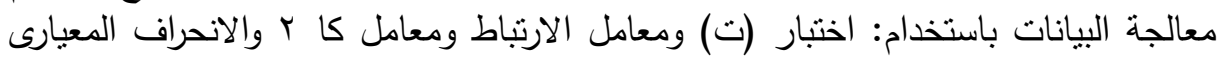

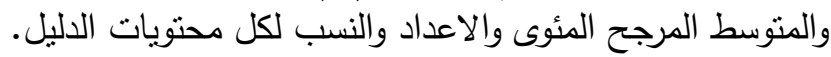

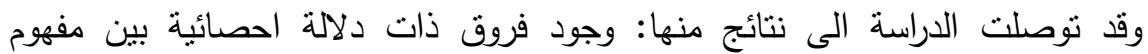

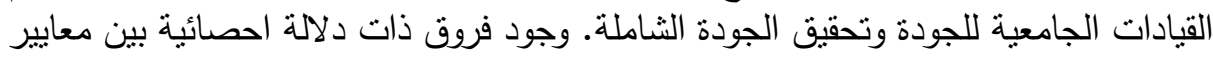

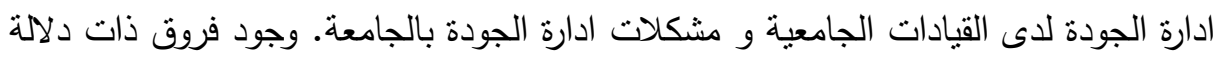
احصائية بين استراتجيات القيادات الجامعية لتحقيق نظم إدارة الجودة الثاملة لأهدافها وفعاليتها وعائد تحقيق الجودة الثاملة.

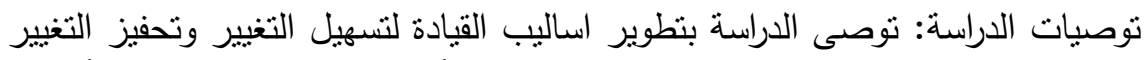
وتوليد وتوجية التغيير فلا نوجد ممارسة قبادية واحدة هي الأفضل للجامعة في جميع الأوقات.

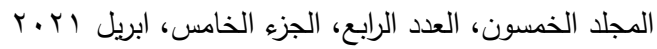

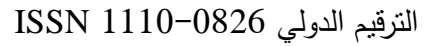




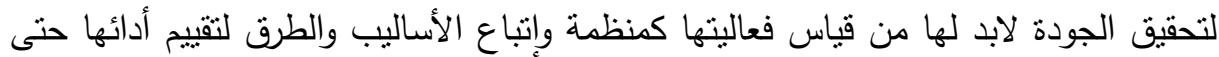

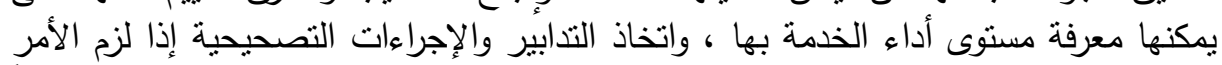

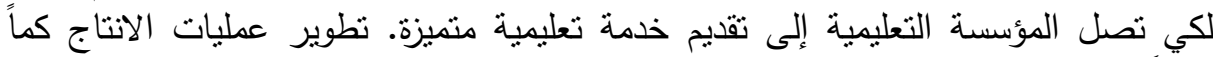

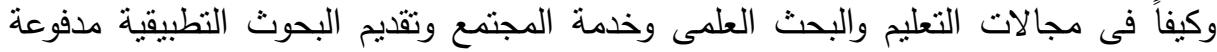
الأجر بما يستهدف فى النهاية خدمة المجتمع وتتمية البيئة وتحقيق والهدائة أهدافة القومية. ضرورة

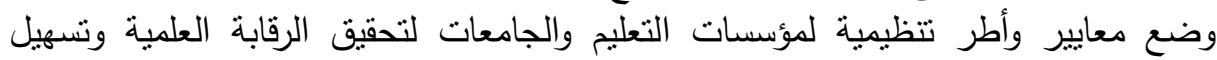

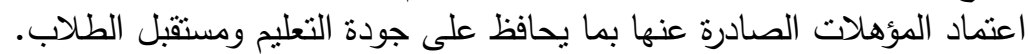

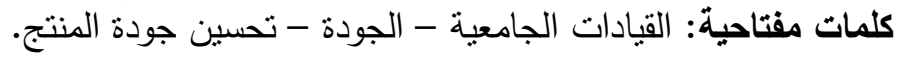

\section{$\sin$}

تعد القيادات الجامعية من أبرز أعضاء المنظومة الإدارية الجامعية ومن أهم عناصرها حيث" تتسم القيادات الإدارية والأكاديمية فى المؤسسة الجامعية ، ممنلة بمختلف كلياتها

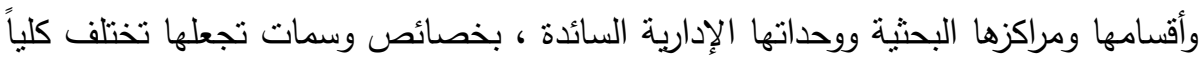
عن القيادات لمؤسسات إنتاجية أو خدمية ، الأمر الذى يظهر تأثنيره على معايير وآليات تعيين واختيار تلأك القيادات.

وتعتبر القبادات الجامعية الأداة التى يمكن من خلالها تحقيق جودة التعليم الجامعى، فإذا توفرت الإدارة الجيدة والتى تقوم بالعملية الإدارية من تخطيط وتتظيم وتوجيه ورقابة للأداء

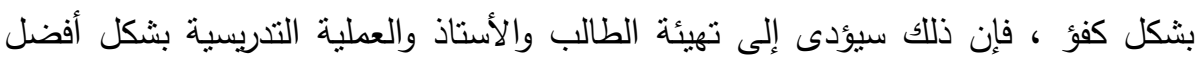

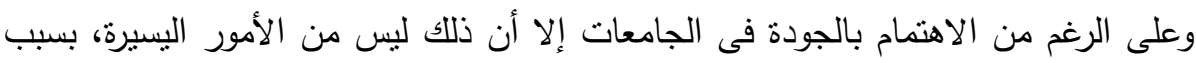

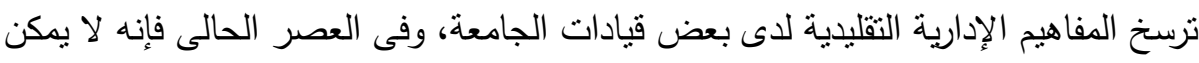

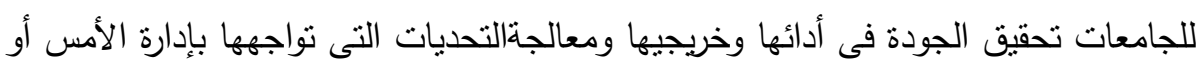
الإدارة التقليدية حيث تحتاج جهود تحسين الجودة تغيراً فى الأساليب التى تعمل بمقتضاها

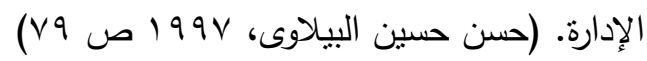

كما أن الجودة أحد أهم الوسائل والأساليب لتحسين نوعية التعليم والإرتقاء بمستوياته فى التى العصر الحالى، الذى بطلق عليه بعض المفكرين عصر الجودة، فلم تعد الجودة ترفاً ترنو إليه 344

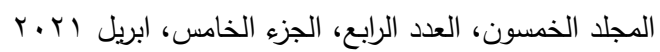

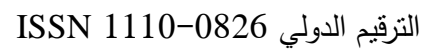




$$
\begin{aligned}
& \text { مجلة العلوم البيئية } \\
& \text { معهد الدراسات والبحوث البيئية - جامعة عين شمس بـ } \\
& \text { سماح رجب عبد القادر وآخرون }
\end{aligned}
$$

المؤسسات التعليمية أو بديلاً تأخذ به أو تتركه الأنظمة التعليمية ، بل أصبحت ضرورة ملحة

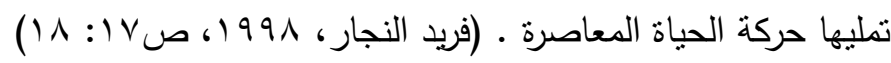
ومن ناحية أخرى تعتبر الهيئة القومية لضمإن جودة التعليم والاعنماد ثمرة المجهودات المخططة لإصلاح وتطوير التعليم في مصر فهي الجهة المسئولة عن نشر ثقافة الجودة في

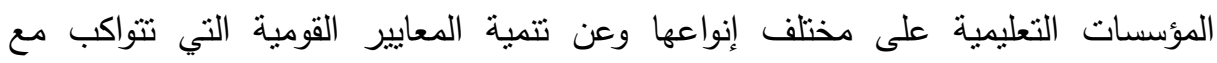
المعايير القياسية الدولية لإعادة هيكلة نظم التعليم في هذه المؤسسات وتحسين جودة مدخلاتها ومخرجاتها على النحو الذي يؤدى إلي كسب ثقة المجتمع بصفة عامة والطالب الجامعى

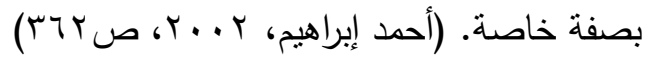

\section{and}

يعيش المجتمع المصري الآن مرحلة انتقالية هامة، يسعى فيها إلى النهضة والتقدم

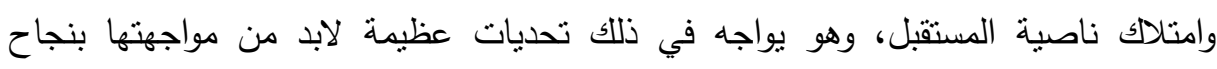
لتحقيق النهضة والتقدم، فقد اعتبرت القيادة السياسية التعليم الركيزة الأساسية في معركة التقام

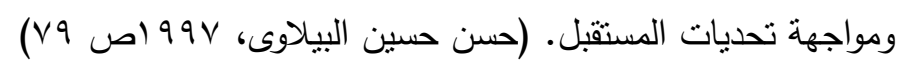

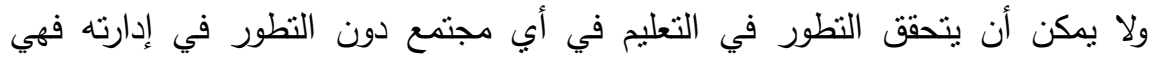
العنصر الأساسي في تطوير التعليم ومن ثم ضرورة أن تتغير الإدارة التعليمية لمواكبة الجديد.

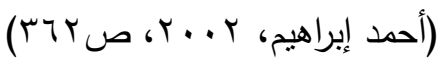

ومن ثم يعتبر الاهتمام بالأداء الإداري للقيادات الجامعية أحد أهم أثنكال وطرق مواجهة

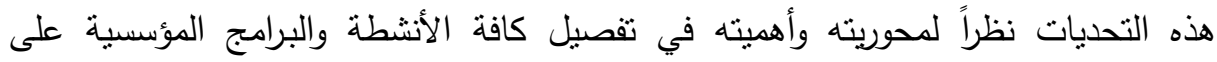
مستوى الأقسام والكليات والجامعات، فالقيادات الجامعية تعتبر أداة التغيير والتطوير بالجامعة، لهُبه

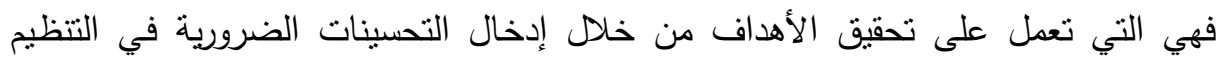

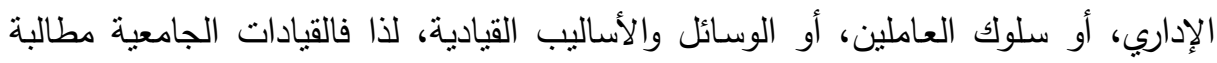
بأن تكون قيادات فاعلة تمنلك المهارات التي تجعلها قادرة على أداء دورها القيادي بكفاءة

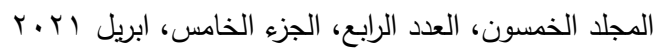

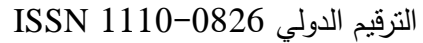




$$
\begin{aligned}
& \text { مجلة العلوم البيئية } \\
& \text { معهز الدراسات والبحوث البيئة - جامعة عين شمس لفس آلئس } \\
& \text { سماح رجب عبد القادر وآخرون }
\end{aligned}
$$

وفاعلية وهذا لن يحدث إلا من خلال إدارة التغيير وقيادته بالجامعات ـ وبالتالى فإن الأداء

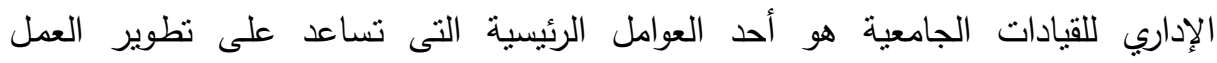
بالجامعات وتحقيق أهدافها.

ولما كانت قضية جودة التعليم لم تلق الاهتمام المطلوب في العديد من الدول النامية

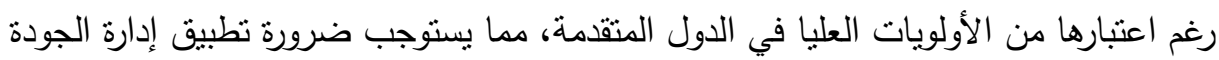
الثاملة في إدارة التعليم المحلية في مصر ومن ثم تطبيقها على تعليم مرحلة الطفولة المبكرة.

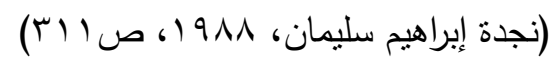
بينما يشير واقع الأداء الإداري للقيادات الجامعية الى أن هنالك العديد من المشكلات

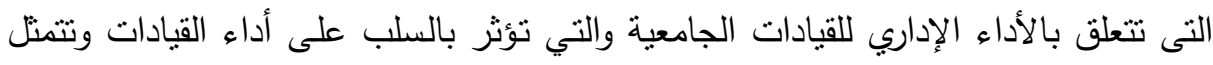

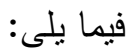
- عدم تمكن الجامعات من وضع تتظيماتها وهياكلها، وتحديد قواعد وإقرارات العمل بها،

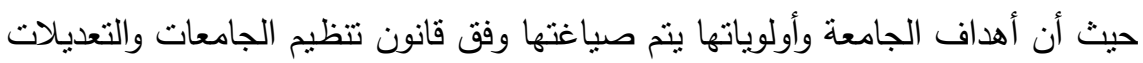
القانونية المتلاحقة له. - - - سبطرة الطابع النمطي التقليدي على الإدارة الجامعية. - شروط ومتطلبات شغل الوظائف القيادية بالجامعة تتصف بالادرة بامعهية بالعمومية وعدم الدقة، فلا يتضمن مؤهل متخصص، أو دورات تدريبية في مجال الإدارة الجامعية.

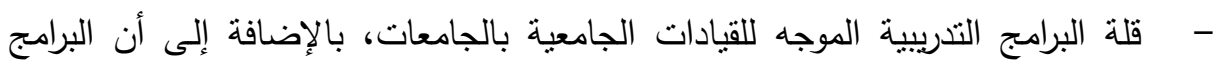
المتاحة تتسم بالتقليدية الثديدة وتقتقد للحداثة.

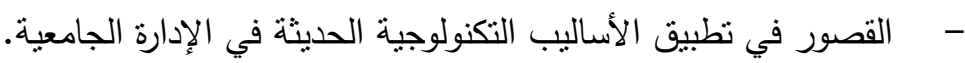

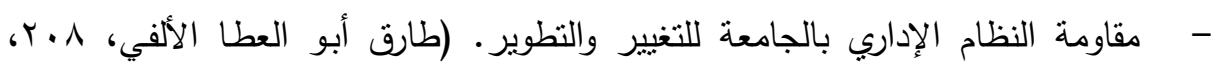
$(r+1)$ - - المركزية الثنديدة في الإدارة الجامعية، وفقدان استقلالية الوحدات الجامعية في النواحي

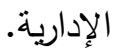




$$
\begin{aligned}
& \text { مجلة العلوم البيئية } \\
& \text { معهد الدراسات والبحوث البيئية - جامعة عين شمس لئس } \\
& \text { سماح رجب عبد القادر وآخرون }
\end{aligned}
$$

- - الروتين والتمسك بحرفية اللوائح والقوانين لدى بعض القيادات في إنجاز مهامهم.

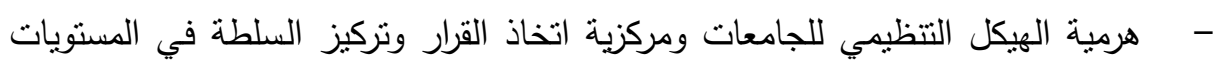

$$
\text { الأعلى في الهرم الإداري. }
$$

- - مود وتقادم الهياكل التنظيمية بالجامعات، وعدم وضوح خطوط الاتصال وتداخلها.

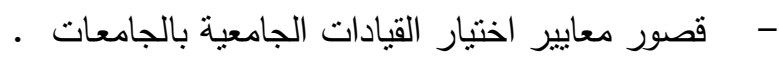

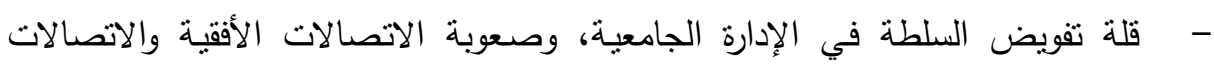
الرأسية الصاعدة والهابطة.

- - تدني مستوى الاتصال الإداري على مستوى الجامعة أو الكلية أو القسم وعدم فاعليته،

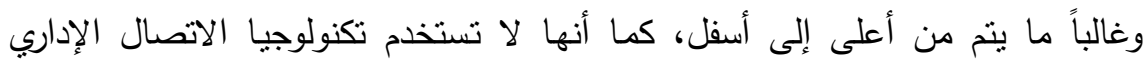

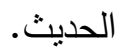
- - سيادة ثقافة الأفراد داخل الجامعة، وغياب ثقافة النظام المؤسسي عند القيادات سواء

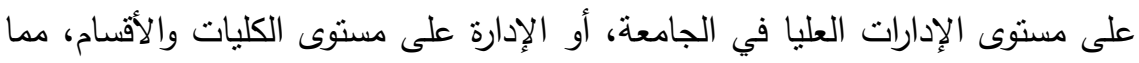
يتطلب نشر ثقافة النظام المدرسي وتقديم برامج نوعية للمستويات المختلفة بين العاملين.

\section{أسئلا الهمهيه}

• ما العلاقة بين القيادات الجامعية وتحسين جودة المنتج؟

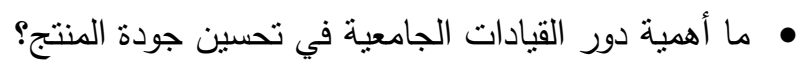

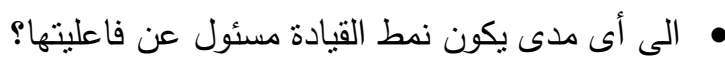

\section{أهفا اهخ المهمث}

$$
\text { التعرف على ملى مفاهيم الجودة ومعاييرها. }
$$

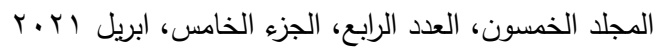


• التعرف على مفهوم تحسين الجودة والمصادر التي تعد منبعا لتحسين الجودة، بالإضافة إلى فوائدها وأهدافها. • التعرف على مبادئ تحسين الجودة وأبعادها وخصائصها ومحدداتها. • التعرف على خطوات تحسين الجودة ومراحلها. الوصول إلى تصور مستقبلي لتحسين جودة الإدارة الجامعية في مصر .

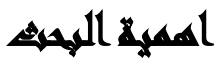

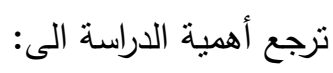

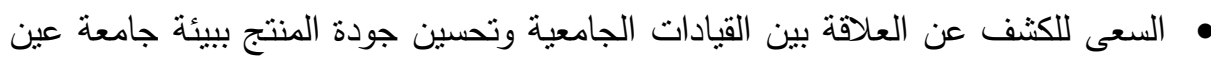
شمس وهو الذى لم تتتاولة الدراسات الكيفية أو الكمية بشكل كبير والتى حاولت الدراسة الراهنة سد الثغرات النظرية والكمبة لموضوع الدراسة.

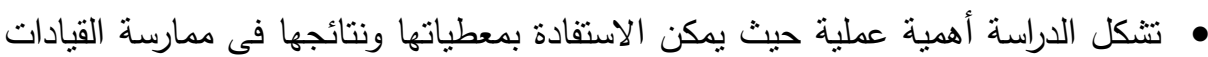
الجامعية لعطلها وخاصة ما يتعلق بتحسين جودة المنتج.

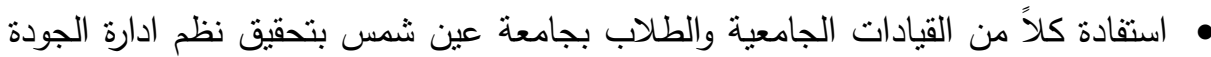

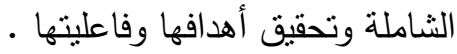
• كون الدراسة الراهنة باطارها الكمى والكيفى تمنل تحفيزاً للارسين فى استدامة اجراء

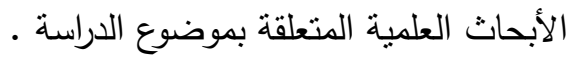

\section{A}

تحددت مجالات الدراسة الثلاثة (المكانى، البشرى، الزمنى) وذلك على النحو النالى:

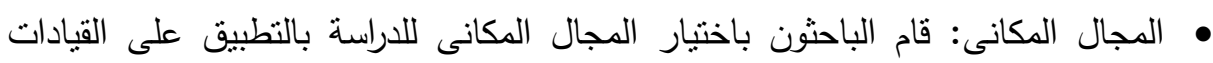
الجامعية وطلاب جامعة عين شمس. 
• المجال البشرى: يتمثل المجال البشرى للدراسة الحالية على النحو التالى: عينة من تحليل مضمون محاضر اجتماعات مجلس جامعة عين شمس. لبنس

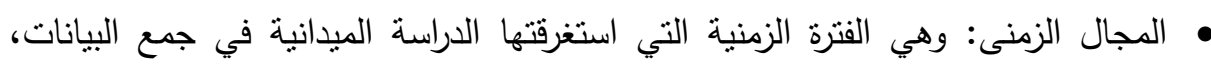

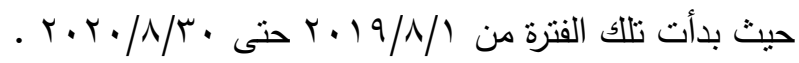

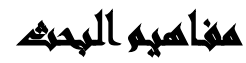

القيادات الجامعية:

مفهوم القيادة: عبارة عن قيام الثخص بعملية إقناع لأثخاص آخرين في مجموعة معينة أو

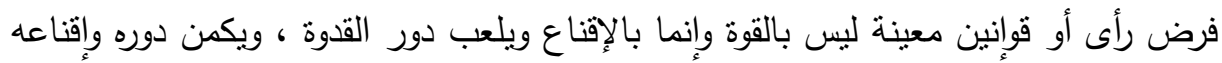

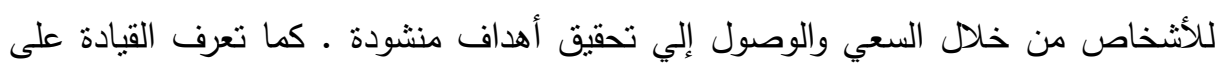

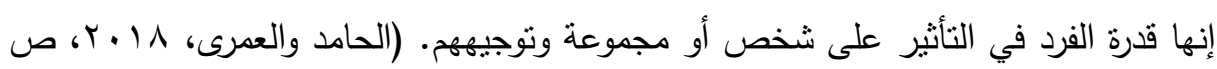

الجودة: يقصد بها درجة الالتزام بالمعايير الحالية والمتفق عليها للمساعدة في تحديد مستوى جيد من الممارسة ومعرفة النتائج المتوقعة للخدمة. كما اتها تكامل الملامح والخصائص لمنتج أو خدمة ما بصورة تمكن من تلبية احتباجات

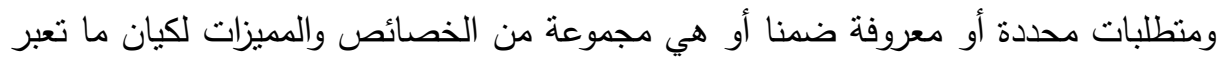
عن قدرتها على تحقيق المنطلبات الدحددة أو المتوقعة من قبل المستفيد ويهنم نظام الجودة بالتحديد الثامل للهيكل التنظيمي وتوزيع المسئوليات والصلاحيات على الموظفين والعمال وإيضاح الأعمال والإجراءات الكفيلة بمراقبة العمل ومثابعته، وكذللك مراقبة وفحص كل ما يرد إلى المنشأة والتأكيد على أن الخدمة قد تم فحصها وأنها تحقق مستلزمات الجودة المطلوبة.

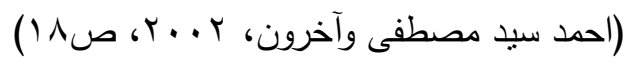

تحسين الجودة: هى الأعمال التي تقوم بها المؤسسة التعليمية لزيادة فعالية الأنشطة والعمليات وعائدها بهذف زيادة نسب النجاح للمؤسسة ولسوق العمل ويتم التحسين من خلال 


$$
\begin{aligned}
& \text { مجلة العلوم البيئية } \\
& \text { معهد الدراسات والبحوث البيئية - جامعة عين شمس لئئ } \\
& \text { سماح رجب عبد القادر وآخرون }
\end{aligned}
$$

تحقيق ضبط افضل لجميع الأنشطة داخل المؤسسة التعليمية أو تتفيذ الأنشطة بطرق جديدة،

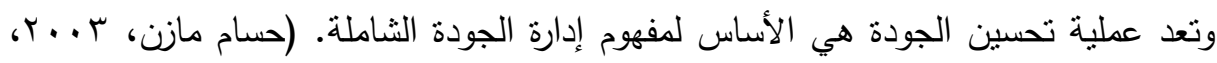

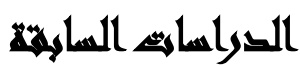

بمراجعة التراث النظرى تبين وجود بعض الدراسات العربية والأجنبية التى قد تساعد معطياتها فى تدعيم السياق المعرفى للاراسة منها: دراسة كلارك، ايمليا كارولين Clarke , Amelia Croline (r . . ب): نظام الادارة البيئية فى الحرم الجامعى لتتفيذ السياسة البيئية الجامعية: جامعة دالهوزى دراسة حالة).

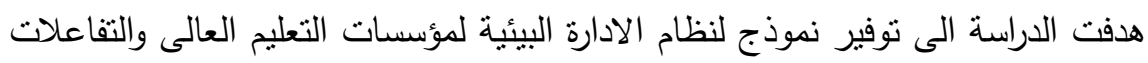

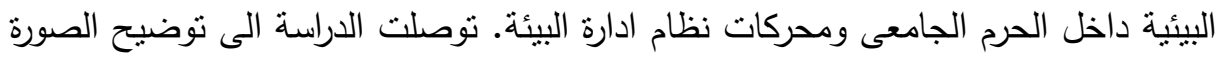
الكبيرة للمشكلات البيئية ودور الجامعة فى التغير البيئى.

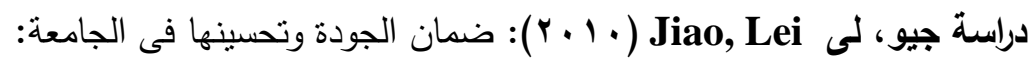
هدفت الدراسة الى التعرف على عملية (مدخلات الطلاب - تدريب الخريجين) وان عملية تخريج الطلاب هى نهاية عملية الجودة برمتها، والوقوف على أسباب تجاهل الدور المهج لاصحاب المصلحة الخاريجين فيما يتعلق بضمان جودة الجامعة وتحسينها. وتوصلت الدراسة الى أن ضمان الجودة يكون من خلال تحليل نظرية المعلومات ونظرية النظم ونظرية التحكم ونظرية ادارة الجودة الثاملة ونظرية أصحاب المصلحة للتمكن من بناء أسس التغذية المرندة للمعلومات الخاصة بالجامعة.

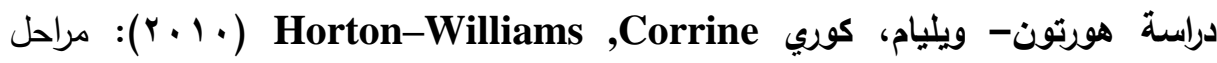
استراتيجية قيادة التعليم العالى التى تتعلق بالاستدامة البيئية داخل الحرم الجامعى ككليات

$$
\text { والجامعات الامريكية. }
$$

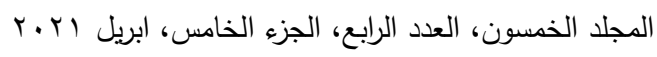

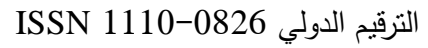




$$
\begin{aligned}
& \text { مجلة العلوم البيئية } \\
& \text { معهد الدراسات والبحوث البيئية - جامعة عين شمس بـ } \\
& \text { سماح رجب عبد القادر وآخرون }
\end{aligned}
$$

هدفت الدراسة الى توثيق مراحل تتفيذ استراتيجية القيادة البارزة المستخدمة فى الحرم الجامعى فى الولايات المتحدة وتطوير فهم شامل للاستدامة البيئية والتعرف على نقاط القوة والضعف للتقييم والتقويم المستخدمين فى الحرم الجامعى فى الولايات المتحدة.

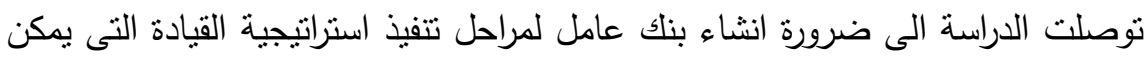

$$
\text { استخدامها من قبل قادة الجامعات على المستوى الاقليمى أو العالمى. }
$$

دراسة هابير، بايج Haber , Paige ( 11 (1 ) ): تصورات القيادة: تحليل فهم طلاب الكلية لمفهوم القيادة.

هدفت الدراسة الى تطوير القدرات القيادية لدى الطلاب من خلال نطوير المناهج الدراسية للتعامل مع نتائج تطوير القيادة .

توصلت الدراسة الى انه يجب على المسئولين وأعضاء هيئة التدريس تحديد قيم القيادة التى يرغبون فى تطويرها فى طلابهم بشكل واضح ودراسة برامج القيادة والفرص المتاحة

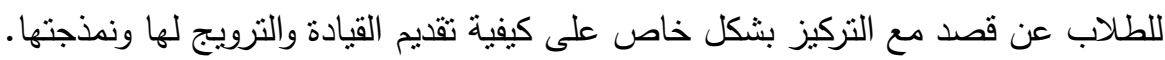
وكانت نتائج الدراسة على النحو التالى: - ظهرت اختلافات كبيرة فى موضوعات القيادة الطلابية حسب الجنس والعرق والعمر . - ظهر عدد من المتغيرات البيئية كمنتبئات مهمة للمواضيع المدرجة. - يجب على المسئولين وأعضاء هيئة التدريس تحديد قيم القيادة التى برغبون فى تطويرها

$$
\text { فى طلابهم بشكل واضح. }
$$

- دراسة برامج القيادة والفرص المتاحة للطلاب عن قصد مع التركيز بشكل خاص على

$$
\text { كيفية تقديم القيادة والترويج لها ونمذجنها. }
$$

دراسة سامح عوض الله السيد (10 • ب): مدى فاعلية التدريب على برامج الجودة وتأثيره في

كفاءة الجودة التعليمية والبيئة بالنطبيق على المعاهد العلمية.

هدفت الدراسة الى رصد أهم المشكلات التي تواجه التدريب وعناصر العملية التهاية التعليمية

في إطار تتفيذ حجم لتوازن ومعايير الجودة الثاملة وتحديد أهم الاحتباجات التدريبية التي

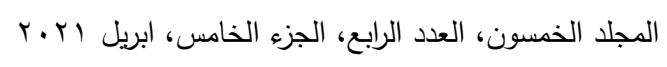

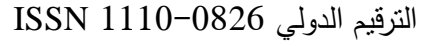


تضمن كفاءة نطبيق معايير الجودة الثاملة في المجال الأكاديمي وفقا لادراكات عناصر العملية التعليمية وكذلك طرح الروئة المستقبلية لأثر التدريب مع الجودة الثشاملة علي مسار العملية التعليمية في المجال الإداري.

وتوصلت الدراسة الى: اولاً: ضرورة الإسراع بنطبيق البرامج النوعية اللازمة وتطبيقها في

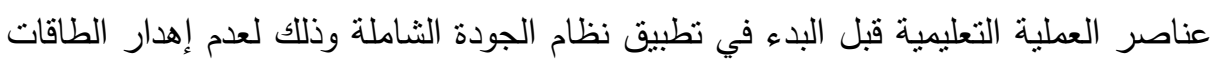
البشرية لعدم تطبيق نظام الجودة .

ثنانيًا: ضرورة إجراء دراسات مستقبلية في الجودة الثاملة في ضوء مناء متغيرات مستويات أعضاء هيئه التدريس وكانت نتائج الدراسة على النحو التالى:

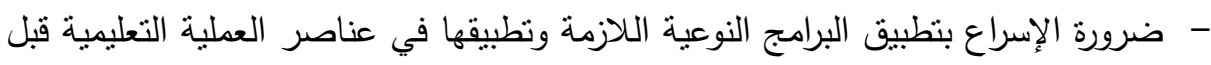
البدء في تطبيق نظام الجودة الثشاملة وذللك لعدم إهدار الطاقات البشرية لعدم تطبيق نظام الجودة .

- ضرورة إجراء دراسات مستقبلية في الجودة الثاملة في ضوء متغيرات مستويات أعضاء

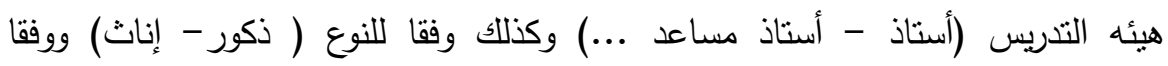
للتخصصات العلمية وجد من خلال الدراسة اختلاف وتباين ردود فعل الطلاب وأعضاء هيئه التدريس والعاملين وفقا لطبيعة تخصصاتهم العلمية. - ضرورة ربط الاهتمام بدور الإعلام في التوعية بأهمية برامج التدريب علي الجودة الثاملة

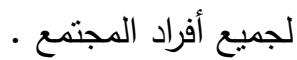

ثالثاً: أن تخصص الكليات ميزانية للبرامج التدريبية التي تفيد حاجة العمل الفعلية والعمل

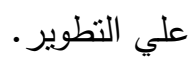

دراسة لمياء محمود رجائى مرموش (Y V P Y): إطار مقترح لاستخدام نظم الجودة البيئية كمدخل لرفع تنافسية المنشآت الخدمية في مصر : دراسة علي الجامعات المصرية.

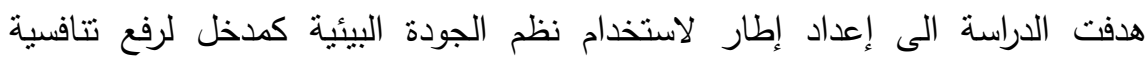
الجامعات المصرية ، وذلك من خلال توصيف نظم الجودة البيئية فى الجامعات المصرية 352

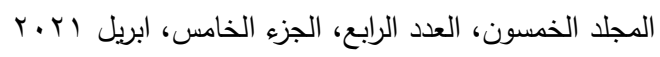

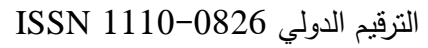


الحكومية والخاصة ، ودراسة طبيعة العلاقة بين مجموعة العوامل البيئية الداخلية والخارجية وتطبيق نظم الجودة البيئية فى الجامعات المصرية ، علاوة على ذللك دراسة طبيعة العلاقة بين تطبيق نظم الجودة البيئية وتحسين مستوى جودة الخدمة التعليمية ، وكذلك زيادة تتافسية

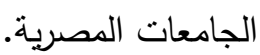

وتوصلت الدراسة الى أهمية تطبيق عناصر الإطار المقترح للاراسة للمحافظة على هلى

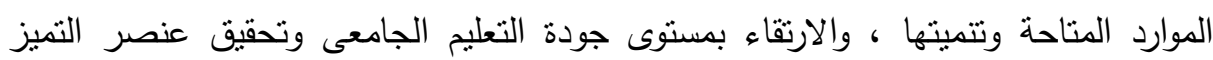
وزيادة القدرة التنافسية للجامعات المصرية. وكانت نتائج الدراسة على النحو التالى: - وجود علاقة معنوية بين مجموعة من العوامل الداخلية والخارجية على إستخدام وتطبيق

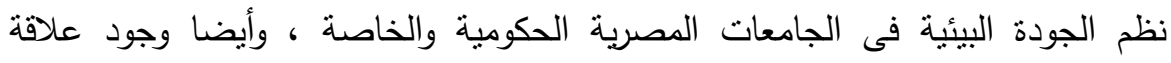
معنوية بين نظبيق نظم الجودة البيئية فى الجامعات المصرية وتحسين مستوى جودة الخدمة التعليمية لتحقيق عنصر الرضا للمستقيدين. - r - وجود علاقة معنوية بين نطبيق نظم الجودة البيئية وزيادة نتافسية الجامعات المصرية

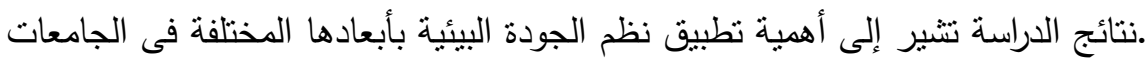

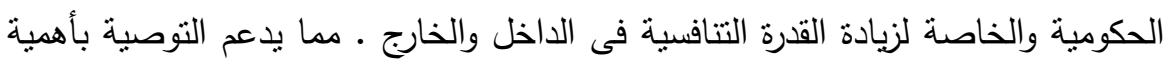

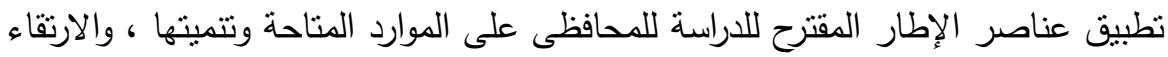
بمستوى جودة التعليم الجامعى وتحقيق عنصر التميز وزيادة القدرة التتافسية للجامعات

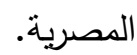

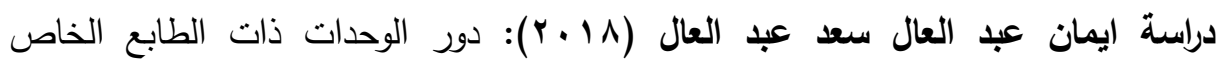
بالجامعات المصرية فى تحسين الخدمة الطلابية: دراسة تقويمية. هدفت الدراسة الى ضرورة أن تتفهم هذه المؤسسات الاحتياجات والتوقعات الحالية والمستقبلية لعملائها من الطلاب ؛من خلال الارتقاء بمستواهم فى جميع الجوانب التعليمية، والنفسية ، والروحية بتوفير نظام متكامل من الخدمات يشمل المساعدات المالية، والرعاية

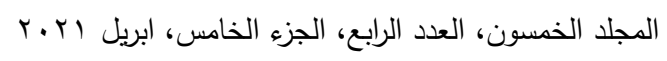

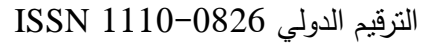


الصحية، والنفسية، والاجتماعية، والاهتمام بذوى الاحتياجات الخاصة ، التى تسهم فى تتمية

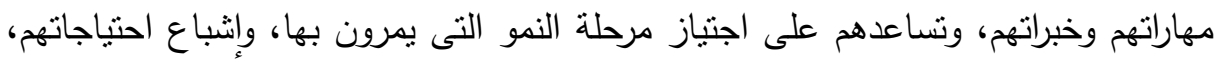

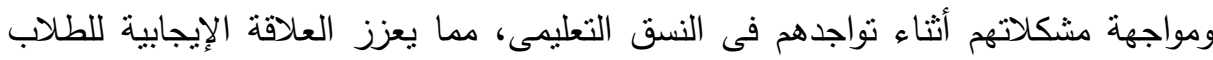

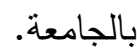

وتوصلت الدراسة الى نطوير عمليات الانتاج كماً وكيفاً فى مجالات التعليم والبحث

العلمى وخدمة المجتمع وتقديم البحوث التطبيقية مدفوعة الأجر بما يستهدف فى النهاية خدمة المجتمع وتنمية البيئة وتحقيق أهدافة القومية .

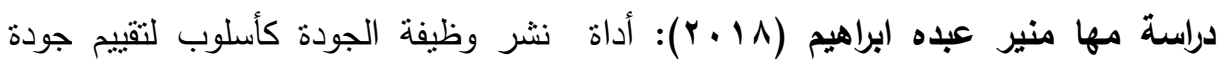
الخدمة التعليمية في مرحلة الدراسات العليا دبلوم إدارة نظم الجودة والإعتماد بجامعة عين ولني شمس نموذجاً.

هدفت الدراسة الى الاهتمام بعمليات تقييم أداء المؤسسات التتموية بما فيها المؤسسات التعليمية عامة والجامعات بخاصة ، ولقد أصبحت عملية تقييم التعليم الجامعى على المستوي

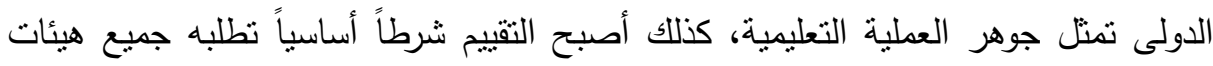
الاعتماد الأكاديمي العالمية. ولقد أدى التغيير السريع والمتصاعد في حركة المستجدات الاقتصادية والتكنولوجية والاجتماعية والسياسية إلى زيادة التأكيد على تحسين مستوى جودة الخدمة التي تقدمها

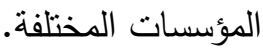

وتوصلت الدراسة ضرورة الارتقاء بأساليب وتقنيات جودة الأداء والمداخل الحاكمة لعملية تحسين نوعية التعليم والارتقاء بمستواه فى العصر الحالى الذى بطلق عليه بعض الدفكرين بأنه عصر الجودة.

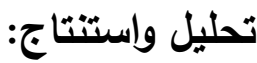
• أكدت الدراسات السابقة على وجود علاقة بين القيادات الجامعية وتحسين جودة المنتج وذللك من خلال العديد من المتغيرات منل الربط بين مفاهيم الادارة البيئية وتتفيذ السياسات ودين 354

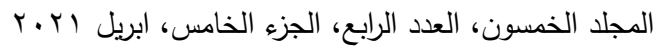

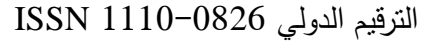


البيئية الجامعية، ضمان الجودة وتحسينها فى الجامعة، استراتيجية قيادة التعليم العالى التى تتعلق بالاستدامة البيئية داخل الحرم الجامعى ككليات والجامعات الامريكية، نشر وظيفة ولهية الجودة كأسلوب لتقييم جودة الخدمة التعليمية في مرحلة الدراسات العليا دبلوم إدارة نظم

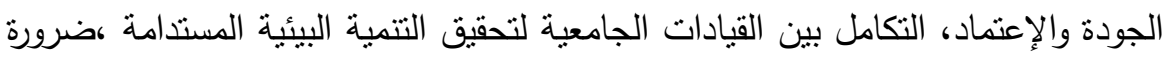

$$
\text { تطوير الأداء الادارى للقيادات الجامعية. }
$$

• استفادت الدراسة الراهنة من كافة المتغيرات التى طرحتها الدراسات السابقة وأستفادات من نوظيفى متغيراتها المختلفة سواء فى الجانب النظرى أو الميدانى للاراسة وأتضح ذلانك جالياً فى المتغيرات المختلفة التى تضمنتها أداة تحليل المحتوى التى استخدمتها الدراسة لاختبار العلاقة بين القيادات الجامعية وتحسين جودة المنتج.

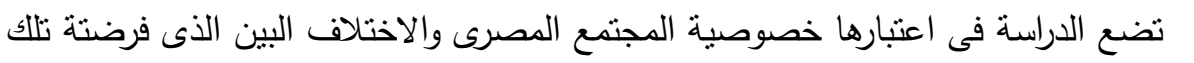

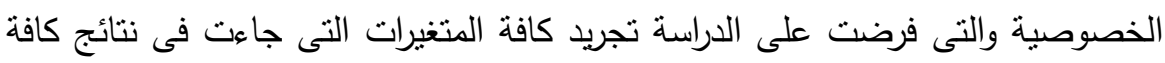

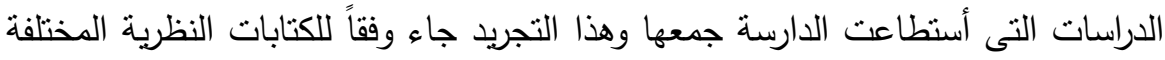
التى عالجت موضوع الدراسة سواء على مستوى القانون الحاكم لتنظيم القيادات الجامعية وعمليات الجودة وذللك وفق ظروف وخصوصية المجتمع المصرى.

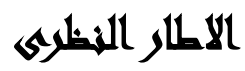

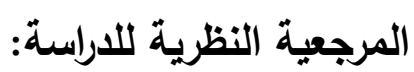

اولاً: اختصاصات الجامعة واستقلاليتها: تتص المادة رقم (1) من قانون تتظيم الجامعات على "'تختص الجامعات بكل مايتعلق بالتعليم الجامعى والبحث العلمى الذى ثقوم به كلياتها

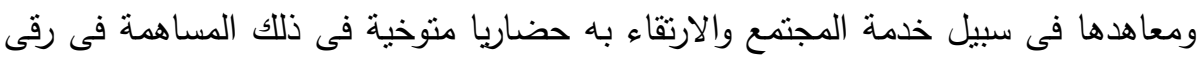
الفكر وتقدم العلم وتتمية القيم الانسانية وتزويد البلاد بالمتخصصين والفنيين والخبراء فى بلى بلهي مختلف المجالات واعداد الانسان المزود بأصول المعرفة وطرائق البحث المتقدمة والقيم الرفيعة ليساهم فى بناء وتدعيم المجتمع الاثتراكى وصنع مستقبل الوطن وخدمة الانسانية

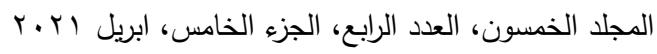

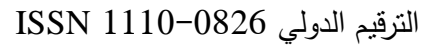


وتعتبر الجامعات بذلك معقلا للفكر الانسانى فى أرفع مستوياته ومصادر لاستثمار وتتمية أهم

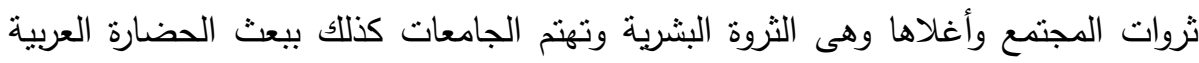
والتراث التاريخى للشعب المصرى وتقاليده الأصيلة ومراعاة المستوى الرفيع للتربية الدينية

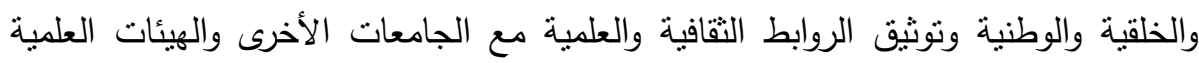

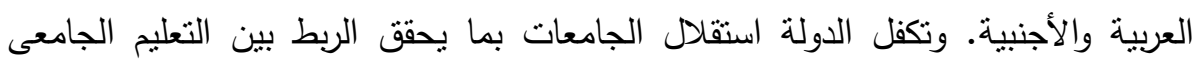

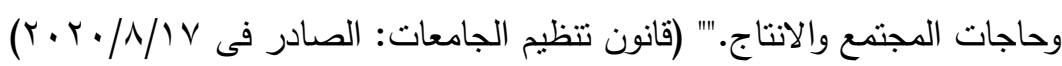

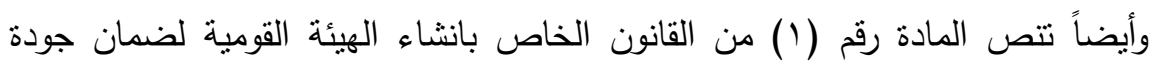
التعليم والاعتماد على "'تتشأ هيئة عامة " تسمى الهيئة القومية لضمان جودة التعليم والاعنماد

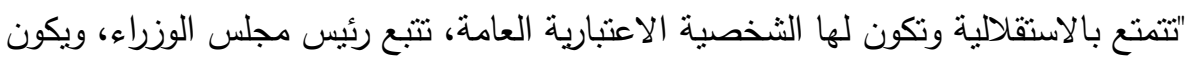
مقرها مدينة القاهرة، وللهيئة أن تتشىء فروعا لها فى المحافظات"' (قانون الهيئة القومية

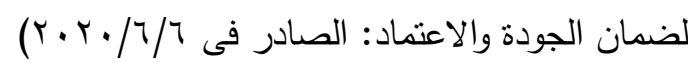
كذا تتص المادة رقم (T) من القانون الخاص بانثاء الهيئة القومية لضمان لهان جودة التعليم والاعتماد على " تهدف الهيئة إلى ضمان جودة التعليم وتطويره المستمر من خلال: بأل

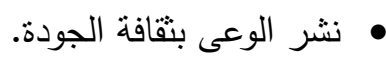

• التسيق مع المؤسسات التعلمية بما يكفل الوصول إلى منظومة منكاملة من المعايير

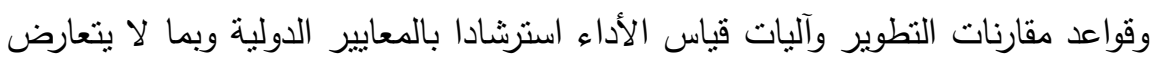
مع هوية الأمة. • دعم القدرات الذاتية للمؤسسات التعليمية للقيام بالتقويم الذاتى. توكيد الثقة على المستوى المحلى والإقليمى والدولى فى جودة مخرجات العملية التعليمية بلهية بما لايتعارض مع هوية الأمة. • الثقويم الثامل للمؤسسات التعليمية وبرامجها طبقا للمعايير القياسية والمعتمدة لكل مرحلة المهاه تعليمية ولكل نوع من المؤسسات التعليمية. (قانون الهيئة القومية لضمان الجودة

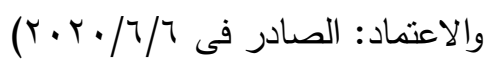


بينما تتص المادة رقم (ع) من القانون الخاص بانثاء الهيئة القومية لضمان جودة التعليم والاعتماد على للهيئة فى سبيل تحقيق أهدافها اتخاذ ما يلزم من إجراءات وقرارات، بلهاء وعلى الأخص: • وضع السياسات والاستراتيجيات الخاصة بضمان جودة التعليم وإعداد تقارير التقويم

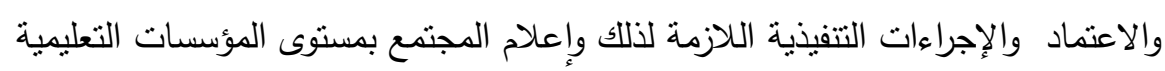
وبرامجها ومدى قدرتها على تقديم الخدمة التعليمية وفقا لرسالتها المعلنة. • وضع آليات نشر الوعى بثقافة الجودة والتطوير لدى المؤسسات التعليمية والمجتمع. • وضع المعايير والإجراءات لقياس مدى استنفاء المؤسسة التعليمية لثروط الاعتماد. • وضع أسس وآليات استرشادية لقيام المؤسسات التعليمية بالتقويم الذاتى.

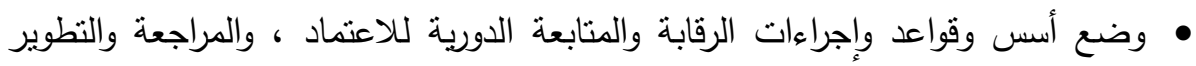
المستمرلها فى ضوء المتغيرات التربوية والعلمية.

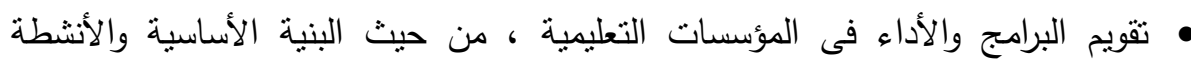

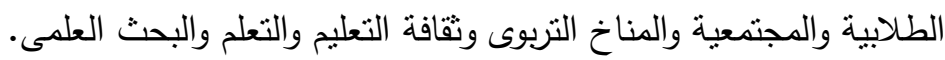

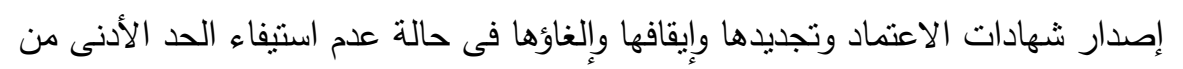
شروط الاعتماد. تقديم المشورة للمؤسسات التعليمية التى لم تحقق المستويات المطلوبة من الجودة ، وذلك

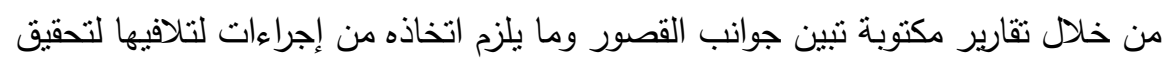

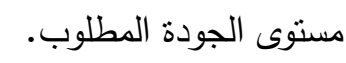
مراجعة وتظوير المعايير القياسية ومؤشرات قياس عناصر جودة التعليم بالتتسيق مع جميع الجهات صاحبة المصلحة والمستقيدين من الخدمة التعليمية.

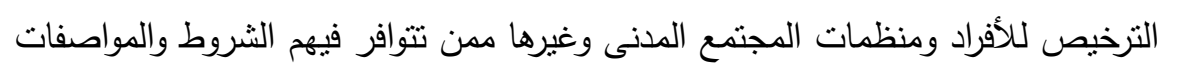
التى تحددها الهيئة بممارسة أعمال التقويم والقيام بزيارات المراجعة للمؤسسات التعليمية

$$
\text { واستعانة الهيئة بهم فى هذه الأعمال. }
$$

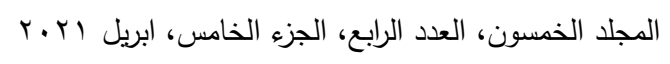

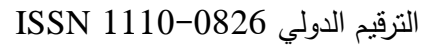


كما تتص المادة رقم (V) من قانون تتظيم الجامعات على "'الجامعات هيئات عامة ذات

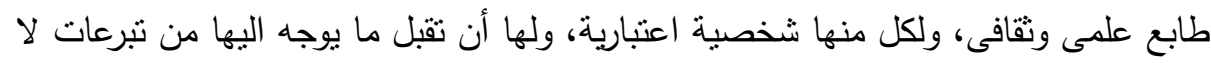

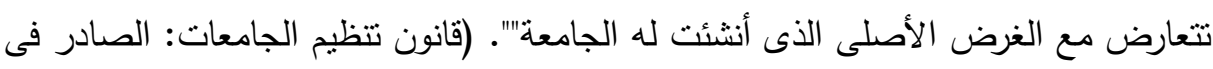
$(r \cdot r \cdot / \Lambda / \Lambda \mathrm{V}$

يتضح من خلال النصوص القانونية السالف سردها بأن الاطار التشريعى منح الجامعة

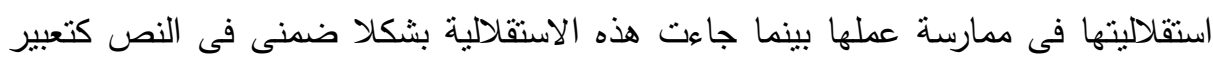

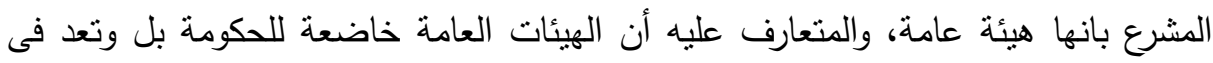
بعض الأحيان ملكاً لها مثل " الهيئات الانتاجية فى القطاع العام " وذللك على سبيل المثال

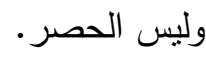
ولما كان ذللك فكان من الأحرى على المشرع أن ينص صراحة على استقلاليتها بالتعبير

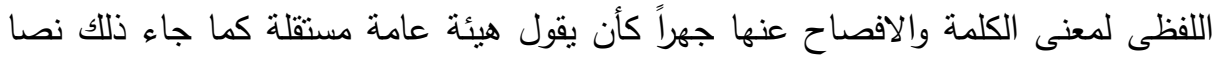
فى المادة رقم (1) من القانون الخاص بانثاء الهيئة القومية لضمان جودة التعليم والاعتماد.

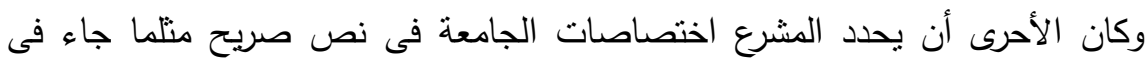
العديد من القوانين المختلفة التى حددت اختصاصات هيئات أومصالح عامة تحديداً مفصلاً القيادات الجامعية داخل الهيكل التتظيمى للجامعة. ثانياً: القيادات الجامعية على مستوى الجامعة: تتص المادة رقم (سام) من قانون تتظيم

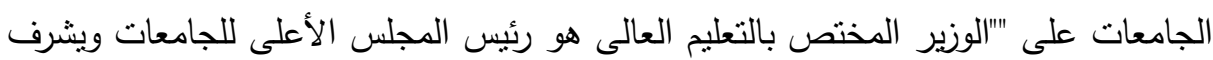

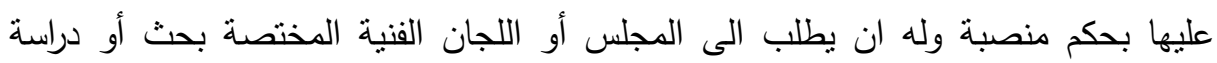
موضوعات معينة وخاصة الموضوعات المتصلة بالسياسة العامة للتعليم الجامعى وربطها

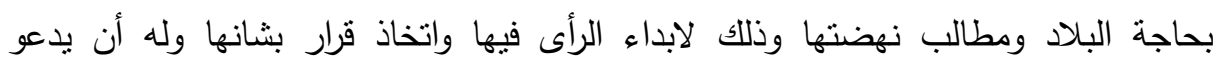

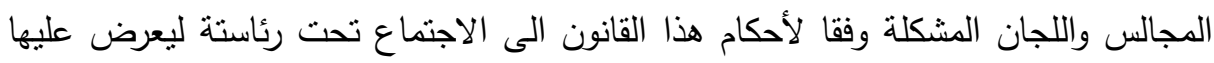

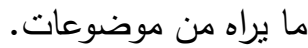


وله أن يطلب من رئيس الجامعة المختصة التحقيق فى الوقائع التى يحيلها اليها وذلك طبقا للقواعد والاجراءات المنصوص عليها فى هذا القانون وموافاتة بتقرير عن نتيجة التحقيق. ( قانون تتظيم الجامعات: الصادر فى (Y. Y./N/IV) بينما تتص المادة رقم (ع () من قانون تتظيم الجامعات على "'اتتولى المجالس والقيادات

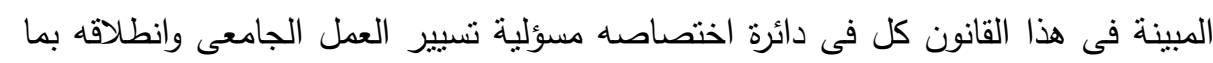
يحقق أهداف الجامعة فى حدود القوانين واللوائح والنظم المقررة. (قانون تتظيم الجامعات:

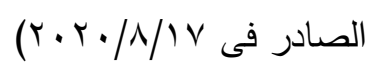

يتضح من النصوص القانونية السالف سردها أن المشرع حدد وأفصح صراحةً عن طبيعة القيادات الجامعية بعضها ببعض كما حدد لها اختصاصاتها علاوة على اضافة لجان فنبة تتصف بصفة الدوام أو لبعض الوقت لبحث الموضوعات التى تدخل فى اختصاصها ، كما لها

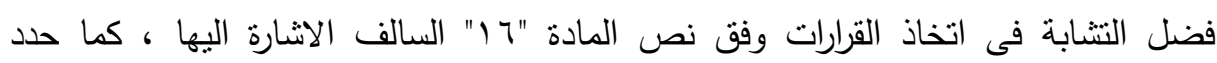
اختصاصات مجلس الجامعة على سبيل الحصر والتى جاء حصرها فى مسائل متفرقة منل

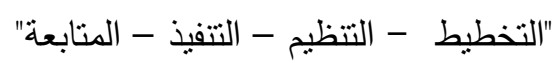

كما أوجب القانون أن تكون القرارات داخل مجلس الجامعة بشكل تتظيمى يوجب عرض التهابه القرارات على المجلس الموقر كم حدد اختصاصات رئيس الجامعة ونوابة على سبيل الحصر .

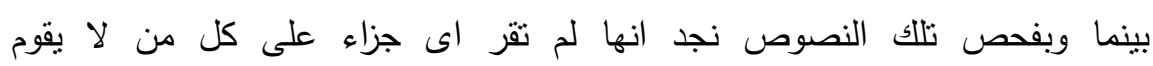
باختصاصاته وفق النصوص السالف ذكرها والتىى جاءت على سبيل الحصر ، ولما كان ذلك الك

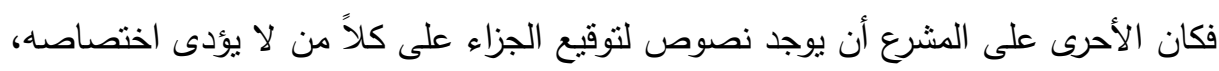

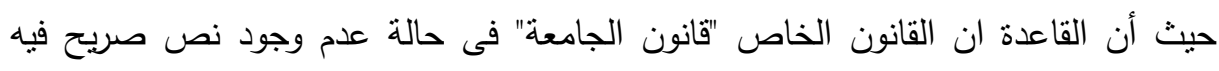

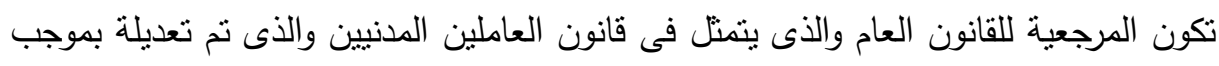

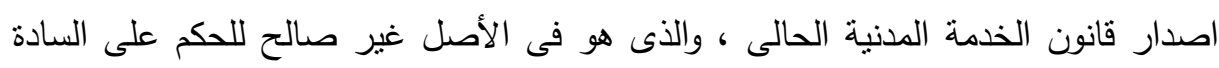

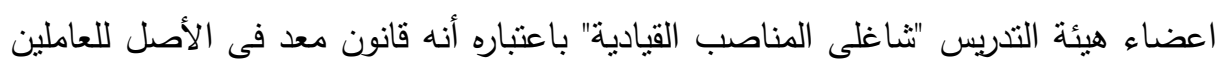

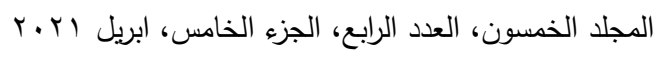

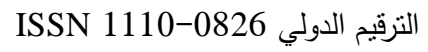




$$
\begin{aligned}
& \text { مجلة العلوم البيئية } \\
& \text { معهد الدراسات والبحوث البيئية - جامعة عين شمس بـ } \\
& \text { سماح رجب عبد القادر وآخرون }
\end{aligned}
$$

فى الوظائف الادارية وهو ما يختلف مع طبيعة الكادر الخاص الذى أختص به المشرع السادة اعضاء هيئة التدريس العاملون بالجامعة.

ومن ثم فكان الواجب على المشرع ان يضع نصوص صريحة للعقاب والمحاسبة والتقويم

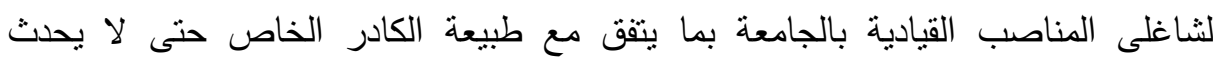
تعارض بين تلك الطبيعة وطبيعة الوظائف الادارية النى ينظمها قانون الخدمة المدنية.

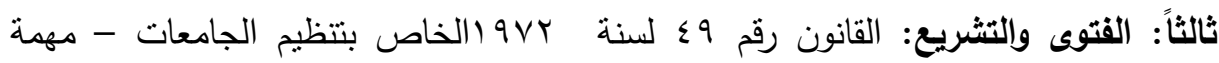
تخطيط ورسم السياسة العامة للتعليم الجامعى واقامة التتسيق بين الجامعات فى أوجة نشاطها

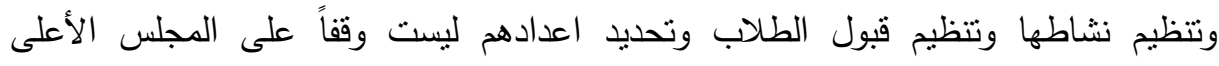

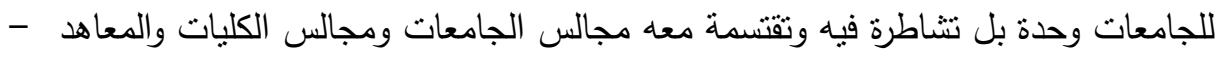
يحق لكل منها ممارسة ذلك الاختصاص واداء تلك المهمة فى حدود الاطار الذى أولاه اياه

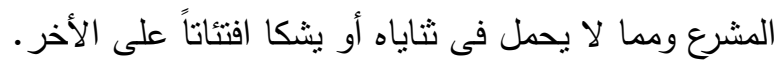

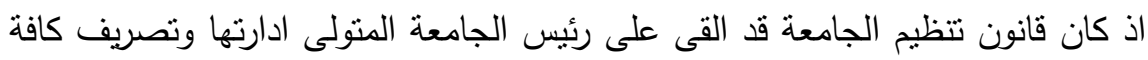

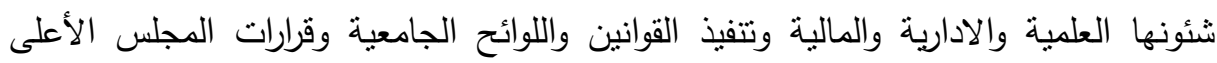

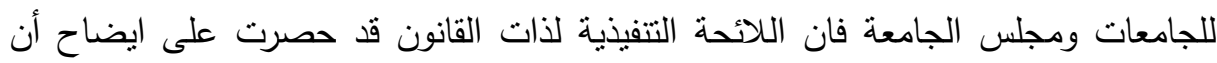
يكون تصريف رئيس الجامعة لنشئونها فى حدود السياسة التى برسمها كل من المجلس الأعلى

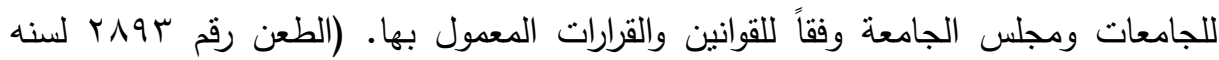

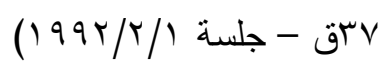

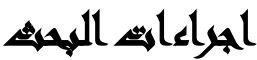

منهج البحث: أعتمد الباحثون على استخدام المنهج الوصفى التحليلى. أدوات البحث: حدد الباحثون اداة الدراسة فى دليل تحليل مضمون محاضر اجتماعات مجلس الجامعة المرنبطة بالعلاقة بين القيادات الجامعية وتحسين جودة المنتج ببيئة جامعة عين شمس خلال الفترات الزمنية المحددة. 
ويفيد تحليل المضمون في التصنيف والوصف المنظم للمادة المراد تحليلها سواء كانت

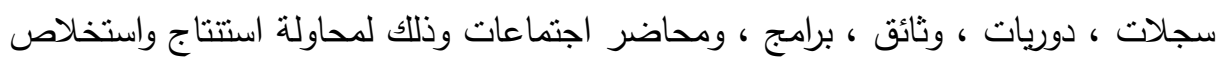
الحقائق منها. الوصف العام لأداة الدراسة: قامت الباحثة باستخدام دليل تحليل المضمون كأداة للدراسة حيث

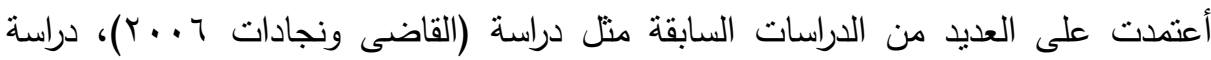

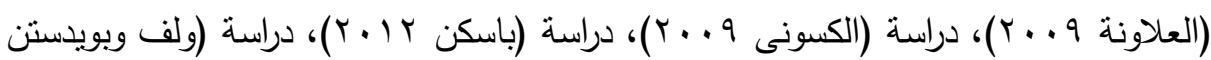

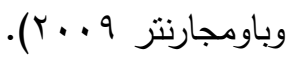
وقد تضمنت الأداة على بيانات أولية تتمنل فى أولاً: فئة الشكل:

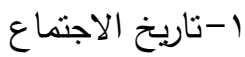
r ب عدد الصفحات r-عدد السطور بالصفحة الواحدة ع - عدد العضاء الحاضرين والغائبين 0- عدد الموضوعات المطروحة 7- أهدد الموضوعات المؤجلة

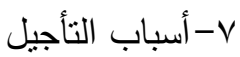
ثانباً: فئة المضمون: 1- 1 - 1شكلات ادارة الجودة بالجامعة

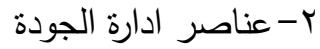

ץ- هدف القيادات الجامعية لتحقيق نظم ادارة الجودة لهدافها وفعاليتها ع - استراتيجيات القيادات الجامعية لتحقيق نظم ادارة الجودة الثاملة لأهدافها وفعاليتها 0-مفهوم القيادات الجامعية للجودة 7-الاساليب المستخدمة من القيادات الجامعية لتحقيق الجودة

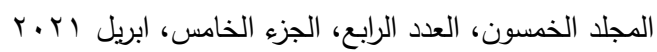
361

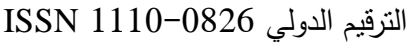


- V

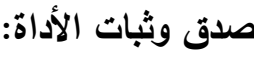

الثبات: حيث اعتمد الباحثون في حساب ثبات دليل تحليل المضمون على معامل ثبات

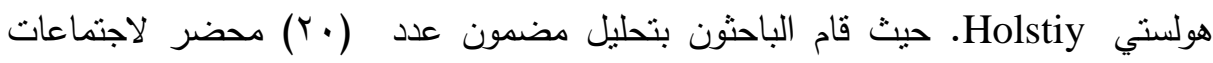

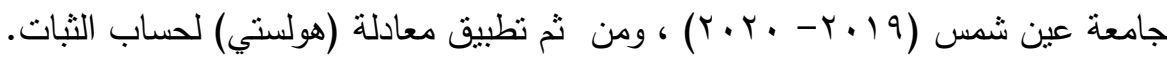
صدق الأداة: حيث قام الباحثون بعرض دليل اليثل تحليل المضمون على عدد (• (1) من أعضاء

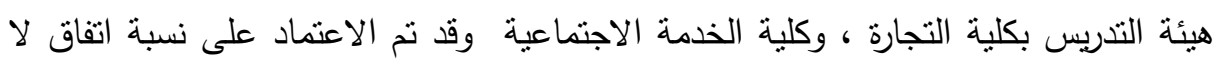

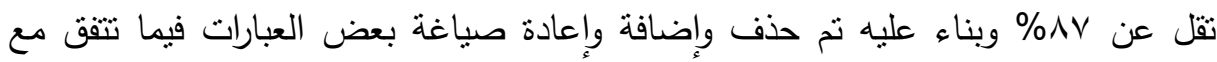
الواقع الفعلي لمتغيرات الدراسة. وصف عينة البحث: شملت عينة البحث كما هو موضح بالجدول تحليل مضمون محاضر اجتماعات مجلس جامعة عين شمس. النتائج الاحصائية للبحث: جدول (1): كا؟ الفارقة لعدد الموضوعات المطروحة للنقاش بمحاضر مجلس جامعة عين

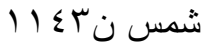

\begin{tabular}{|c|c|c|c|c|c|c|}
\hline \multirow{2}{*}{ قيمة (كا؟) } & \multirow{2}{*}{ الانحراف } & \multirow{2}{*}{ المتوسط } & \multirow[b]{2}{*}{$\%$} & \multirow[b]{2}{*}{ ك } & & \multirow[b]{2}{*}{ e } \\
\hline & & & & & & \\
\hline$* 5861.949$ & .0556 & 2.999 & $\vee \Lambda, Y$ & $\Lambda 9 \varepsilon$ & $r-1$ & 1 \\
\hline *6817.530 & .3065 & 1.093 & $11, \mathrm{~V}$ & $1 \pi \varepsilon$ & r-r & r \\
\hline$* 891.624$ & .1941 & 1.153 & 1,1 & 110 & $9-7$ & $r$ \\
\hline
\end{tabular}

يوضح الجدول السابق أن: تبين من الجدول السابق ان عدد الموضوعات المطروحة للنقاش بمحاضر مجلس جامعة عين شمس وقد تقدم (1-r) حيث تحنل النسبة الاكبر يليها 


$$
\begin{aligned}
& \text { مجلة العلوم البيئية } \\
& \text { معهد الدراسات والبحوث البيئية - جامعة عين شمس لئ } \\
& \text { سماح رجب عبد القادر وآخرون }
\end{aligned}
$$

وبإيجاد الفروق ودلالتها بإستخدام كاب الفارقة لعدد الموضوعات المطروحة للنقاش

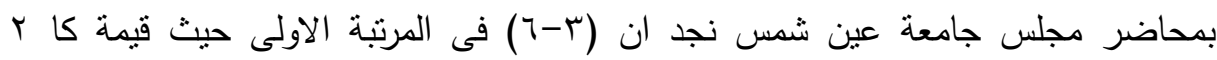

\begin{tabular}{|c|c|c|c|c|c|c|}
\hline \multirow{2}{*}{ قديمة (كاب) } & \multirow{2}{*}{ الانحراف } & \multirow{2}{*}{ المتوسط } & \multirow[b]{2}{*}{$\%$} & \multirow[b]{2}{*}{ ك } & & \multirow{2}{*}{ p } \\
\hline & & & & & & \\
\hline 27.801 & .1106 & 1.483 & 43.7 & 499 & 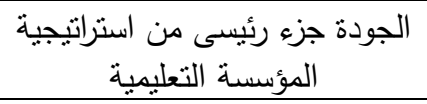 & 1 \\
\hline $5670.109 *$ & .0483 & 1.194 & 50.6 & 578 & وتوزيع المسئوليع العاملين ومشاركتهم في المديرين & r \\
\hline $3683.333^{*}$ & .1222 & 1.057 & 19.0 & 217 & 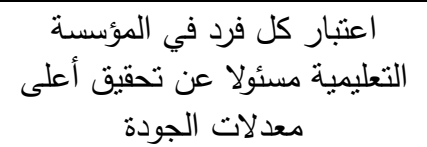 & r \\
\hline $60.257 *$ & .0811 & 1.026 & 38.3 & 438 & مناقثة لجان تقصى الحقائق & $\varepsilon$ \\
\hline 4819.596* & .3005 & 1.270 & 20.6 & 236 & وذوفير قيادة واعية وديموقراطية بالجودة الثاملة & 。 \\
\hline 29.367 & .0633 & 1.288 & 45.1 & 516 & تطبيق فلسفة التحسينات المستمرة & 7 \\
\hline $1847.865 *$ & .1330 & 1.277 & 51.6 & 590 & التزكيز على جميع جوانب الجودة & $\mathrm{V}$ \\
\hline $610.860 *$ & .0556 & 1.261 & $\cdot$ & $\cdot$ & الاهتمام بالتدريب المستمر & $\Lambda$ \\
\hline $534.664 *$ & .3065 & 1.503 & . & . & التخطيط والتوجيه والتقييم الذاتى & 9 \\
\hline $637.386 *$ & .1941 & 1.128 & . & . & المنافسة مع المؤسسات التعليمية & 1 . \\
\hline $421.949 *$ & .0540 & 1.307 & 1.3 & 15 & التعاون وسيادة روح الفريق & 11 \\
\hline $130.928 *$ & 32490 . & 1.205 & 61.9 & 707 & المقارنات التجديدية & ir \\
\hline
\end{tabular}

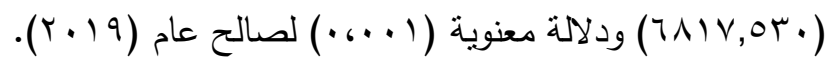

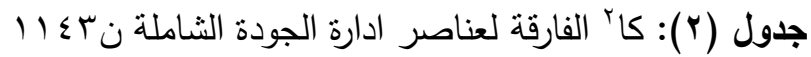




$$
\begin{aligned}
& \text { مجلة العلوم البيئية } \\
& \text { معهد الدراسات والبحوث البيئية - جامعة عين شمس لئن } \\
& \text { سماح رجب عبد القادر وآخرون }
\end{aligned}
$$

يوضح الجدول السابق أن: نبين من الجدول السابق ان عناصر ادارة الجودة الثشاملة والاكثر شيوعا لدى اعضاء مجلس الجامعة هى (مشاركة جميع العاملين والمديرين وتوزيع المسئوليات ومشاركتهم في اتخاذ القرارات) حيث تحتل النسبة الاكبر يليها (تطوير مشاركة الموردين المناسبين لنظام إدارة الجودة الثاملة) بينما الاقل ورودها هى (التخطيط والتوجيه والتقييم الذاتي). وبإيجاد الفروق ودلالتها بإستخدام كاr الفارقة لعناصر ادارة الجودة الثاملة نجد ان

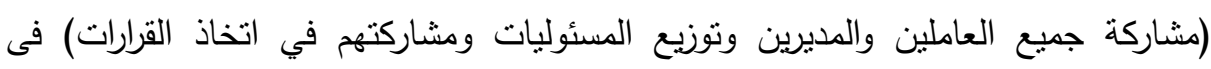

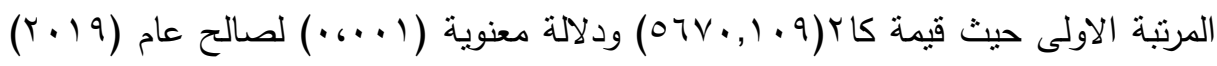
وقد يرجع ذللك الى الازدواجية الادارية فى مختلف المهام بالجامعة. 
مجلة العلوم البيئية

معهد الدراسات والبحوث البيئية - جامعة عين شمس لئس

سماح رجب عبد القادر وآخرون

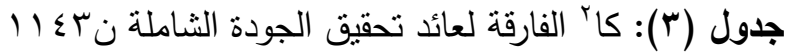

\begin{tabular}{|c|c|c|c|c|c|c|}
\hline \multirow{2}{*}{ قيمة (كاب) } & \multirow{2}{*}{ ال المعيارى } & \multirow{2}{*}{ المتوسط } & \multirow[b]{2}{*}{$\%$} & \multirow[b]{2}{*}{ ك } & & \multirow[b]{2}{*}{ م } \\
\hline & & & & & & \\
\hline $5095.425^{*}$ & .2964 & 1.056 & 2.7 & 31 & 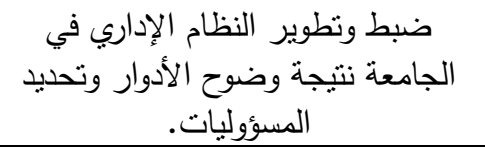 & 1 \\
\hline $4868.014 *$ & .3372 & 1.243 & 1.0 & 11 & الجوانب الجسمية والعقلية والاجتماعية فيعة النقية & r \\
\hline 11683.330* & .3638 & 1.259 & .1 & 1 & 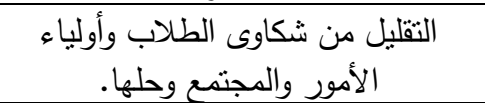 & r \\
\hline $9773.756 *$ & .2821 & 1.285 & - & . & زالأداء لجميع الإدارة التعليية ورفع مستوى والمعلمين & $\varepsilon$ \\
\hline $11822.263^{*}$ & .4773 & 1.07 & 1.9 & 22 & الوفاء بمنطلبات الطلاب وإرضاء أولياء & 0 \\
\hline $11620.092 *$ & .1659 & 1.111 & .8 & 9 & تمكين الإدارة الجامعية من تحليل الطيلة الطيلة & 7 \\
\hline $7623.047 *$ & .2780 & 1.025 & .3 & 3 & 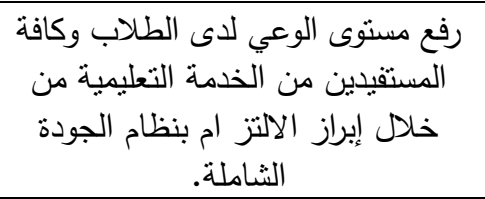 & V \\
\hline $11742.772 *$ & .4241 & 1.039 & 4.1 & 47 & تحقيق الترابط والتكامل بين جميع العمليق بريق. & $\wedge$ \\
\hline 11089.494* & .0752 & 1.206 & .6 & 7 & 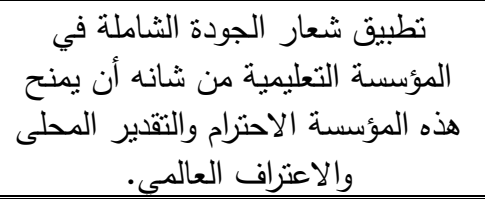 & $q$ \\
\hline
\end{tabular}

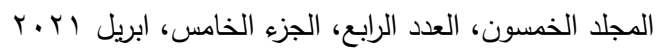

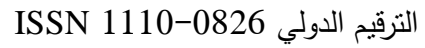


يوضح الجدول السابق أن: تبين من الجدول السابق ان عائد تحقيق الجودة الثاملة

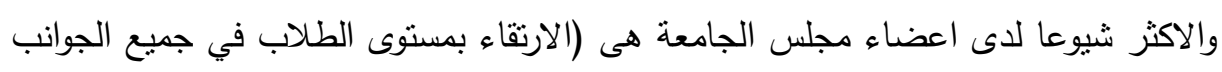

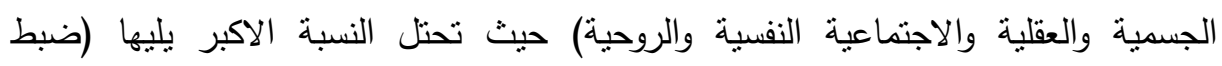
وتطوير النظام الإداري في الجامعة نتيجة وضوح الأدوار وتحديد المسؤوليات) بينما الاقل ورودها هى (التقليل من شكاوى الطلاب وأولياء الأمور والمجتمع وحلها). وبإيجاد الفروق ودلالتها بإستخدام كاب الفارقة لعائد تحقيق الجودة الثاملة نجد النداء (الوفاء

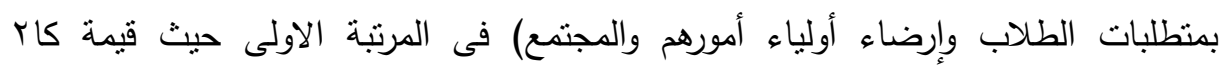

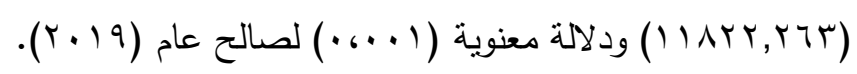
جدول (ء): كا؟ الفارقة لهدف القيادات الجامعية لتحقيق نظم إدارة الجودة الثشاملة لأهدافها

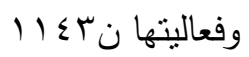

\begin{tabular}{|c|c|c|c|c|c|c|}
\hline \multirow{2}{*}{ قيمة (كا؟) } & \multirow{2}{*}{ المعيارى الانحراف } & \multirow{2}{*}{ المتوسط } & \multirow[b]{2}{*}{$\%$} & \multirow[b]{2}{*}{ ك5 } & & \multirow[b]{2}{*}{ p } \\
\hline & & & & & & \\
\hline $1774.627 *$ & .0811 & 1.337 & $9 r, 0$ & $1.0 \mathrm{~V}$ & رضناء العميل أو الزبون & 1 \\
\hline 4150.615 & .3005 & 1.010 & $r, V$ & M & التحسين المستمر & $r$ \\
\hline 4960.419* & .0633 & 1.091 & $r, r$ & YY & التقويض أو التمكين & $r$ \\
\hline $753.143^{*}$ & .1330 & 1.062 & $r, 0$ & rq & العمل الفريقى & $\varepsilon$ \\
\hline
\end{tabular}

يوضح الجدول السابق أن: تبين من الجدول السابق ان هدف القيادات الجامعية لتحقيق

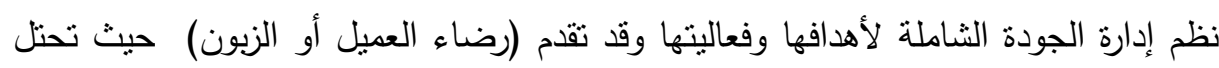

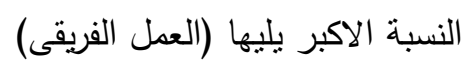

وبإيجاد الفروق ودلالتها بإستخدام كاب الفارقة لهدف القيادات الجامعية لتحقيق نظم إدارة

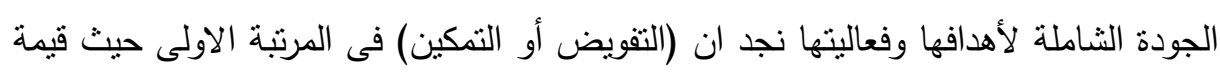

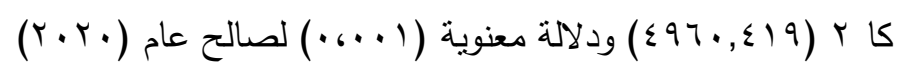

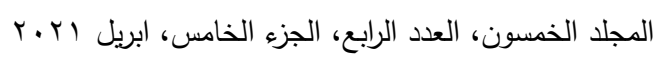

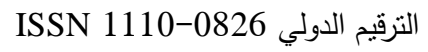


مجلة العلوم البيئية

معهد الدراسات والبحوث البيئية - جامعة عين شمس لهـ

سماح رجب عبد القادر وآخرون

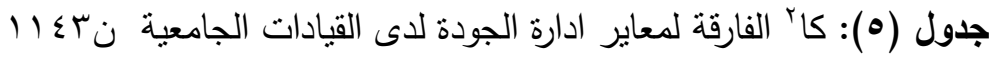

\begin{tabular}{|c|c|c|c|c|c|c|}
\hline \multirow{2}{*}{ قيمة (كاب) } & \multirow{2}{*}{ المعيارى المراف } & \multirow{2}{*}{ المتوسط } & \multirow[b]{2}{*}{$\%$} & \multirow[b]{2}{*}{ ك } & & \multirow[b]{2}{*}{ r } \\
\hline & & & & & & \\
\hline $753.143^{*}$ & 1.00 & 1.035 & $\varepsilon, 7$ & or & الشتراك جميع العاملين في حل آلتئ تواجه المؤسسة. & 1 \\
\hline $2492.552 *$ & 1.002 & 1.003 & 7,7 & $V 4$ & تتمية ثقافة الجودة لدى جميع العاملين & r \\
\hline $4960.419 *$ & 1.179 & 1.062 & 1,7 & 11 & 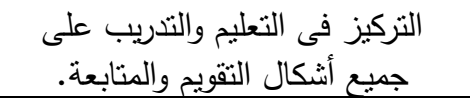 & r \\
\hline $753.143^{*}$ & 1.00 & 1.035 & 0,1 & 01 & استخدام الطرق الإحصائية، والتركيز & $\varepsilon$ \\
\hline $2412.452 *$ & 1.002 & 1.003 & $\lceil\wedge, \wedge$ & $\leqslant \leqslant r$ & 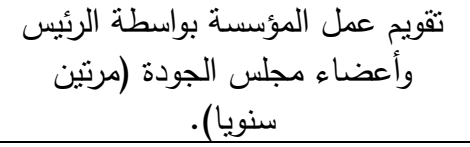 & 0 \\
\hline 4961.419* & 1.179 & 1.062 & $\varepsilon 1, r$ & rvi & 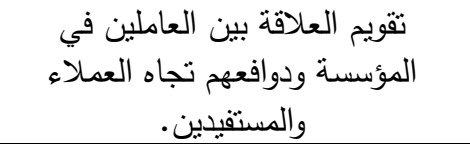 & 7 \\
\hline
\end{tabular}

$6.0>616,1<* * 6, \ldots 1=61<*$

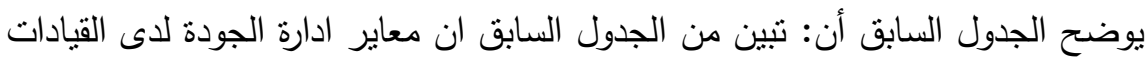

الجامعية وقد تقدم (تقويم العلاقة بين العاملين في المؤسسة ودوافعهم تجاه العملاء والمستقيدين) حيث تحتل النسبة الاكبر يليها (التركيز فى التعليم والتدريب على جميع أنشكال

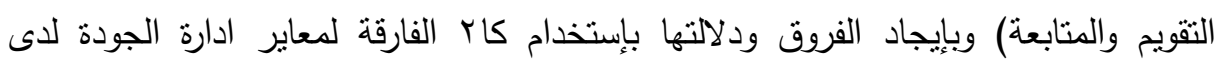
القيادات الجامعية نجد ان (تقويم العلاقة بين العاملين في المؤسسة ودوافعهم تجاه العملاء

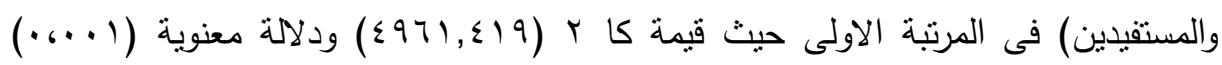

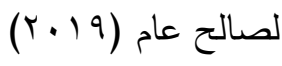




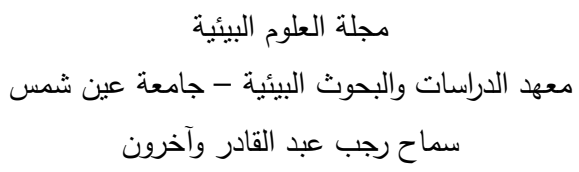

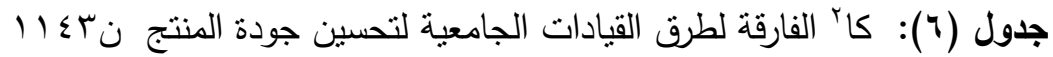

\begin{tabular}{|c|c|c|c|c|c|c|}
\hline قودلالاتها & 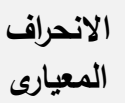 & المتوسط & $\%$ & ك & & b \\
\hline$* 140.3$ & .497 & 1.44 & 7,7 & V4 & دراسة البرامج الناجحة لمنظمات أخرى & 1 \\
\hline$* 4955.2$ & .382 & 1.17 & $\wedge, \vee$ & 99 & وضع أهداف تحسين الجودة الثشاملة & r \\
\hline *10354.0 & .181 & 1.03 & $\varepsilon, 9$ & 07 & 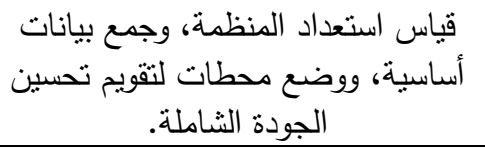 & r \\
\hline$* 3507.7$ & .420 & 1.22 & $I V, \Sigma$ & 191 & إقامة بنية مساعدة. & $\varepsilon$ \\
\hline *10586.3 & .168 & 1.02 & $1 \%, \varepsilon$ & lor & 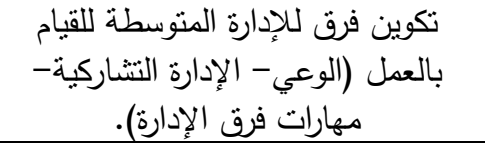 & ० \\
\hline$* 8886.2$ & .252 & 1.06 & $19, r$ & YM & 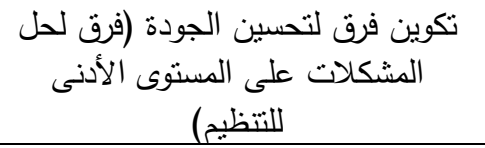 & 7 \\
\hline$* 11533.4$ & .091 & 1.00 & $\wedge, 1$ & 94 & العمل مع العملاء والمزودين لتحسين & v \\
\hline * 11794.4 & .054 & 1.00 & $\wedge, 9$ & $1 \cdot r$ & تكامل أهداف تحسين الجودة في خطة & $\wedge$ \\
\hline *11734.8 & .064 & 1.00 & IY,V & $1 \leqslant 0$ & 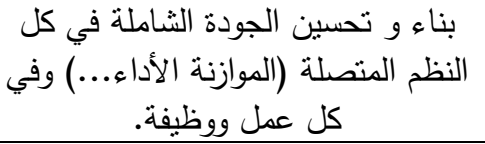 & 9 \\
\hline
\end{tabular}

يوضح الجدول السابق أن: تبين من الجدول السابق ان طرق القيادات الجامعية لتحسين

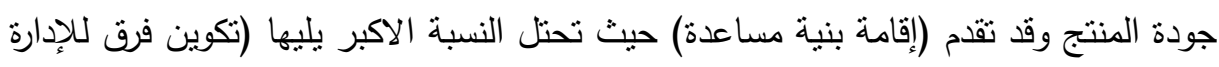
المتوسطة للقيام بالعمل (الوعي- الإدارة التشاركية- مهارات فرق الإدارة). 


$$
\begin{aligned}
& \text { مجلة العلوم البيئية } \\
& \text { معهد الدراسات والبحوث البيئية - جامعة عين شمس لئ } \\
& \text { سماح رجب عبد القادر وآخرون }
\end{aligned}
$$

وبإيجاد الفروق ودلالتها بإستخدام كاب الفارقة لطرق القيادات الجامعية لتحسين جودة المنتج نجد ان (تكامل أهداف تحسين الجودة في خطة استراتيجية للتنظيم وجميع الخطط

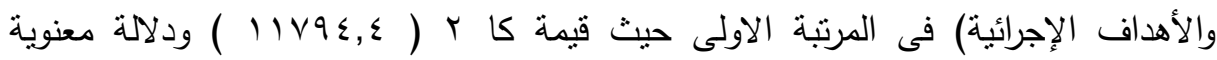

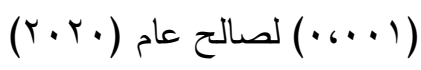

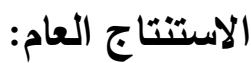

• من خلال عرضنا للاراسات السابقة يتضح وجود علاقة بين القيادات الجامعية وتحسين جودة المنتج وذلك من خلال متغيرات متعددة منل ضمان الجودة وتحسينها فى الجامعة ، نشر وظيفة الجودة كأسلوب لتقييم جودة الخدمة التعليمية، التكامل بين القيادات الجامعية

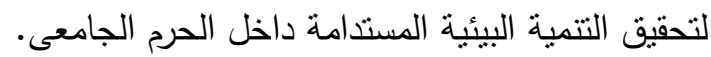

• تجدر الاثارة الى انه لا توجد دراسات عربية كافية تتاولت موضوع الدراسة الحالية.

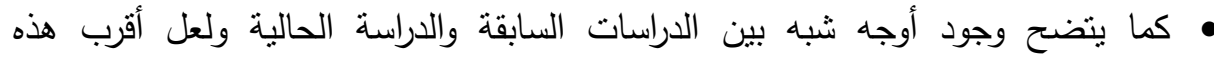

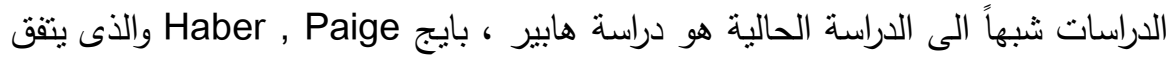
مع الدراسة الحالية فى تطوير القدرات القيادية لدى الطلاب من خلال تطوير المناهج

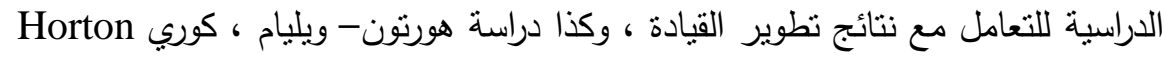
- Williams, Corrine استراتيجية القيادة البارزة المستخدمة فى الحرم الجامعى وتطوير فهم شامل للاستدامة البيئية والتعرف على نقاط القوة والضعف للتقييم والتقويم المستخدمين فى الحرم الجامعى.

\section{تموسيامت المهيث}

توصى الدراسة بنطوير أساليب القيادة لتسهيل التغيير وتحفيز التغيير وتوليد وتوجية التغيير فلا توجد ممارسة قيادية واحدة هى الأفضل للجامعة فى جميع الأوقات .

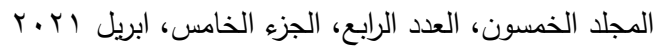

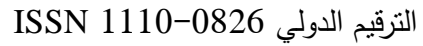




$$
\begin{aligned}
& \text { مجلة العلوم البيئية } \\
& \text { معهد الدراسات والبحوث البيئية - جامعة عين شمس لئ } \\
& \text { سماح رجب عبد القادر وآخرون }
\end{aligned}
$$

• لتحقيق الجودة لابد لها من قياس فعاليتها كمنظمة وإتباع الأساليب والطرق لتقيبم أدائها

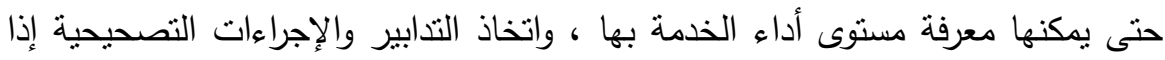
لزم الأمر لكي تصل المؤسسة التعليمية إلى تقديم خدمة تعليمية متميزة.

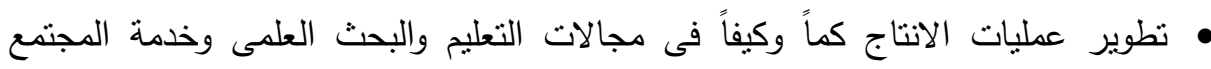

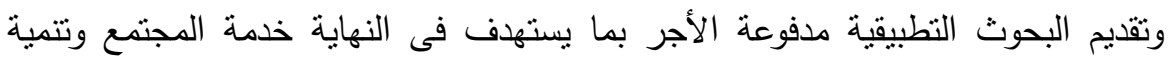
البيئة وتحقيق أهدافة القومية.

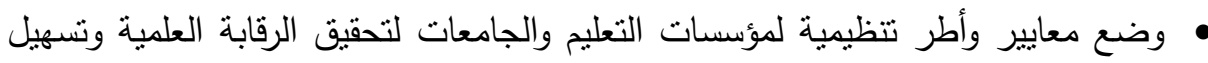
اعتماد المؤهلات الصادرة عنها بما يحافظ على جودة التعليم ومستقبل الطلاب.

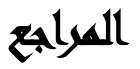

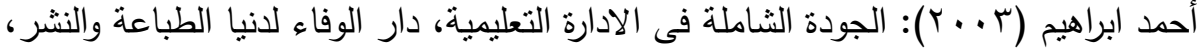

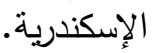

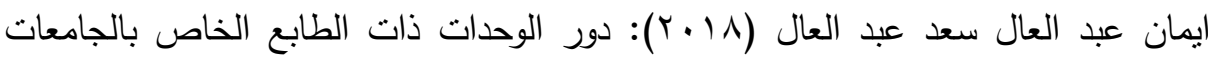

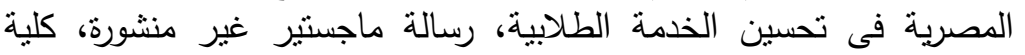

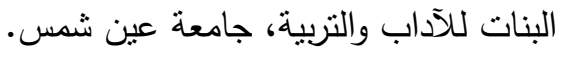

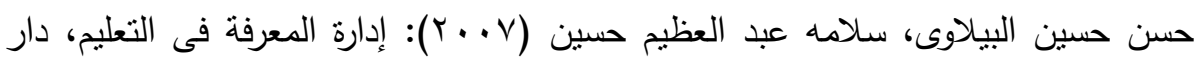

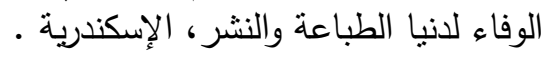

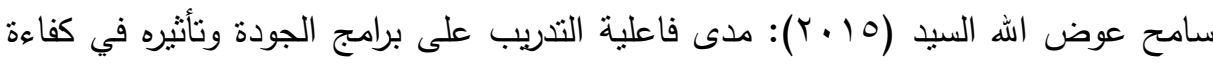
الجودة التعليمية والبيئة بالتطبيق على بلى بعض المبات المعاهد العلمية، رسالة دكتوراة غير منشورة، معهد البحوث والدراسات البيئية، جامعة عين شمس.

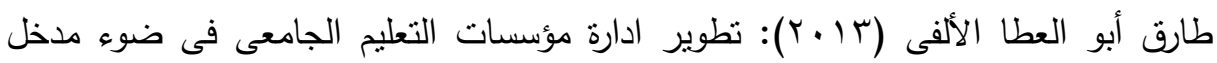

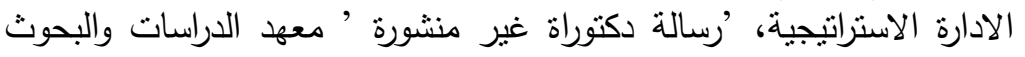

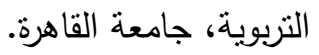

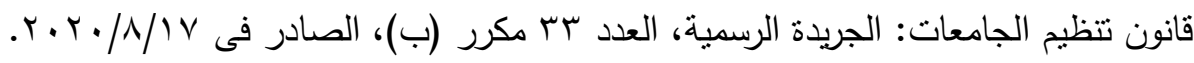


قانون الهيئة القومية لضمان الجودة والاعتماد: الجربدة الرسمية، العدد بr مكرر، الصادر فى $r \cdot r \cdot / 7 / 7$

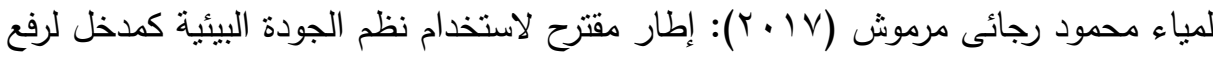
تتافسية المنشآت الخدمية في مصرية، رساتلة دكتوراة غير منشورة، معهد

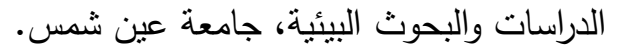

مها منير عبده ابراهيم (1) (Y): أداة نشر وظيفة الجودة كأسلوب لتقييم جودة الخدمة التعليمية في مرحلة الدراسات العليا دبلوم إدارة نظم الجودة والإعتماد بجامعة

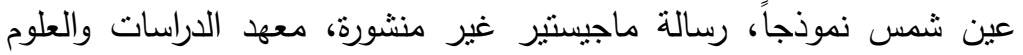
البيئية، جامعة عين شمس.

نجدة ابراهيم (T ( ب): تتظيم ادارى مفترح للتعليم الجامعى المفتوح فى مصر على ضوء خبرات بعض الدول رسالة دكتوراة غير منشورة، كلية البنات، جامعة فينز عين شمس.

Clarke, Amelia Caroline (2002): Campus environmental management system for the implementation of a university environmental policy, M.E.S, Dalhousie UniDalhousie University (Canada), ProQuest Dissertations Publishing.

Haber, Paige (2011): Perceptions of leadership: An analysis of college students' understandings of the concept of leadership, Ph.D, University of San Diego, ProQuest Dissertations Publishing.

Horton-Williams, Corrine D (2010): Higher education leadership stages and strategies that relate to campus environmental sustainability as U.S. colleges and universities, Ph.D,Mercer University, ProQuest Dissertations Publishing.

Jiao, Lei (2010): University quality assurance and enhancement: university external stakeholder information feedback mechanism research, Master, East China Normal University (People's Republic of China), ProQuest Dissertations Publishing.

$$
\begin{gathered}
\text { المجلد الخمسون، العدد الرابع، الجزء الخامس، ابريل الترقيم الدولي 0826-0 } \\
\text { ISSN 1110 }
\end{gathered}
$$




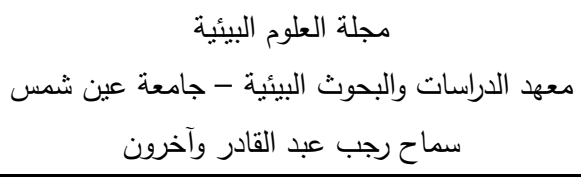

THE RELATIONSHIP BETWEEN UNIVERSITY

\title{
LEADERSHIP AND IMPROVING PRODUCT QUALITY IN THE ENVIRONMENT OF AIN SHAMS UNIVERSITY
}

\author{
Samah R. Abdel Kader ${ }^{(1)}$; Atef A. Hassan ${ }^{(2)}$ and Osama M. Fared ${ }^{(3)}$ \\ 1) Post graduate Student at Institute of Environmental Studies and \\ Research, Ain Shams University 2) Faculty of Law, Ain Shams \\ University 3) Faculty of Commerce, Ain Shams University
}

\begin{abstract}
The Current study aims to define the concept of quality within the University's internal quality assurance system, which targeted teachers, students and policies and from this logic, the importance of this study lies in seeking to uncover the reality of the relationship between university leadership and improving product quality in the environment of Ain Shams University, which did not deal with qualitative or quantitative studies. In large part, the current study tried to fill in the theoretical and quantitative gaps of the subject of study. Where researchers used environmental quality systems as an entry point to raise the competitiveness of universities, by describing environmental quality systems in Egyptian public universities, studying the nature of the relationship between the set of internal and external environmental factors and the application of environmental quality systems in Egyptian universities, in addition to studying the nature of the relationship between the application of quality systems, Environmental and improving the quality of educational service. The researchers also used the analytical descriptive approach and the content analysis of the minutes of the Ain Shams University Council meetings on the relationship between university leaders quality.
\end{abstract}

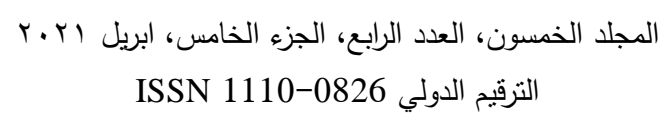




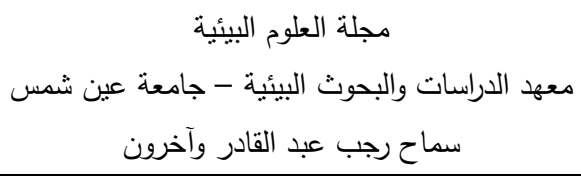

The data were also processed Using: (T) test, correlation coefficient, ka coefficient, standard deviation, mean semantic reference, numbers and percentages for all the contents of the guide.

The study reached conclusions, including the presence of statistically significant differences between the concept of university leaderships for quality. And the achievement of comprehensive quality, the existence of statistically significant differences between the quality management standards of university leaders and the problems of quality management at the university, and the existence of statistically significant differences between the strategies of university leaders to achieve systems. Total quality management for its objectives, effectiveness and the achievement of Comprehensive quality. 